\title{
Relative embeddings: a Circassian puzzle for the syntax/semantics interface
}

\author{
Ivano Caponigro • Maria Polinsky
}

Received: 17 August 2009 / Accepted: 21 December 2009 / Published online: 9 April 2011

(C) The Author(s) 2011. This article is published with open access at Springerlink.com

\begin{abstract}
This paper documents and analyzes the pattern used in the Northwest Caucasian language Adyghe (Circassian) to express what the following five different constructions convey in other languages: headed and headless relative clauses, embedded declaratives, embedded polar interrogatives, and embedded constituent interrogatives. We argue that Adyghe encodes the meanings of all these embedded structures by means of the same syntactic construction, a relative clause. This pervasive use of relative clauses is possible due to mechanisms that are independently attested not just in Adyghe but also in more familiar languages like English. These mechanisms include concealed questions, polarity operators, and nominals such as fact and question that can connect propositional attitude verbs or interrogative verbs with embedded clauses. We suggest that this extensive use of relative clauses in Adyghe is triggered by the absence of non-relative complementizer. We further show that this use is facil-
\end{abstract}

\footnotetext{
We are very grateful to our language consultants Raxmet Eshev, Raxmet Gishev, Svetlana Kinokova, and Mira Unarokova for their help with the language data. This paper owes its initial inspiration to the pioneering findings by Yury Lander and Yakov Testelets, who have been very generous in discussing their findings with us. We are particularly indebted to Peter Arkadiev and Brian O'Herin for their very detailed comments on this work. We would also like to thank Ayla Appelbaum, Daniel Büring, Gennaro Chierchia, Marcel den Dikken, Shin Fukuda, Anastasia Giannakidou, Matt Gordon, Daniel B. Kane, Richard Kayne, Ed Keenan, Christopher Kennedy, Min-Joo Kim, Shin-Sook Kim, Alexander Letuchiy, Eric Potsdam, Greg Scontras, Kirill Shklovsky, Donca Steriade, Virginia Yip, and three anonymous reviewers for helpful suggestions. Parts of this work were presented at SALT 18, WCCFL 27, GLOW 31, CUNY Graduate Center, Zentrum für allgemeine Sprachwissenschaft in Berlin, the University of Chicago, and Yale University. We are solely responsible for all the errors in this paper.
}

\footnotetext{
I. Caponigro ( $\square)$

Department of Linguistics, University of California San Diego, 9500 Gilman Drive, 0108, La Jolla, CA 92093-0108, USA

e-mail: ivano@ucsd.edu
}

M. Polinsky

Department of Linguistics, Harvard University, Cambridge, MA 02138, USA

e-mail: polinsky@fas.harvard.edu 
itated by their morphological visibility: a relativizer realized as a prefix on the verb, verbal affixation, a rich system of applicative heads hosting indirect arguments, and the availability of a case marker suffixed to headless relatives. We conclude by discussing the implications of the Adyghe system for the general design of embedding and subordination in natural language.

Keywords Adyghe (Circassian) - Relative clauses $\cdot$ Headless relatives · Embedded clauses - Declarative clauses · Interrogative clauses · Concealed questions · Polarity operators

$\begin{array}{ll}\text { Abbreviations } \\ \text { ABS } & \text { absolutive } \\ \text { ADN } & \text { adnominal } \\ \text { ADV } & \text { adverbial } \\ \text { APPL } & \text { applicative } \\ \text { BEN } & \text { benefactive } \\ \text { COM } & \text { comitative } \\ \text { COMP } & \text { complementizer } \\ \text { COP } & \text { copula } \\ \text { DIR } & \text { directional } \\ \text { DYN } & \text { dynamic } \\ \text { ERG } & \text { ergative } \\ \text { FUT } & \text { future } \\ \text { IMPF } & \text { imperfective } \\ \text { INF } & \text { infinitive } \\ \text { INSTR } & \text { instrumental } \\ \text { INTERR } & \text { interrogative } \\ \text { INV } & \text { inverse } \\ \text { LOC } & \text { locative } \\ \text { MOT } & \text { motive } \\ \text { NEG } & \text { negation } \\ \text { NOM } & \text { nominative } \\ \text { OBL } & \text { oblique } \\ \text { P } & \text { postposition } \\ \text { PL } & \text { plural } \\ \text { POSS } & \text { possessive } \\ \text { POT } & \text { potential } \\ \text { PRED } & \text { predicate } \\ \text { PRES } & \text { present } \\ \text { REAS } & \text { reason } \\ \text { REC } & \text { reciprocal } \\ \text { REFL } & \text { reflexive } \\ \text { REL } & \text { relativizer } \\ \text { SG } & \text { singular } \\ & \\ & \end{array}$




$\begin{array}{ll}\text { Spec } & \text { specifier } \\ \text { SPEC } & \text { specific } \\ \text { SUBJ } & \text { subject } \\ \text { TEMP } & \text { temporal }\end{array}$

\section{Introduction}

Many familiar languages exhibit the syntax/semantics mapping exemplified by the bracketed strings in (1)-(5), where five syntactically different embedded tensed clauses express five different meanings.

(1) I admire the house [which Le Corbusier built].

(2) [What Le Corbusier built] was not universally liked.

(3) I am confident [that Le Corbusier worked in Cambridge].

(4) She asked [whether Le Corbusier built that house].

(5) She asked [what buildings Le Corbusier built in Cambridge].

More concretely, a headed relative clause like which Le Corbusier built in (1) is mapped to the set of inanimate individuals that Le Corbusier built (cf. Quine 1960 and Montague 1973, a.o.). A free relative like what Le Corbusier built in (2) has been argued to be mapped to the maximal (plural) inanimate individual that Le Corbusier built (Jacobson 1995; Caponigro 2004). An embedded declarative like that Le Corbusier worked in Cambridge in (3) is standardly mapped to the proposition 'that Le Corbusier worked in Cambridge'. An embedded polar interrogative like whether Le Corbusier built that house in (4) is mapped to a set containing the proposition 'that Le Corbusier built that house' and/or its negation 'that Le Corbusier did not build that house'. Finally, an embedded constituent interrogative like what buildings Le Corbusier built in Cambridge in (5) is mapped to the set of propositions that are (true) answers to the question 'What buildings did Le Corbusier build in Cambridge?' (this is addressed in the work stemming from Hamblin's 1973 and Karttunen's 1977 seminal ideas).

These differences in meaning for the embedded tensed clauses correspond to differences in the morphosyntax: the presence or absence of a $w h$-word, a relative pronoun, or an overt complementizer; syntactic transparency (in embedded declaratives) or syntactic opacity (in relatives and interrogatives); and differences in the nature of the complementizer heading the embedded clause.

The pattern above is so common that we may be tempted to think that all languages should have some instantiation of it. But is this really the case? In what follows, we document and analyze a language, Adyghe, that conveys all these meanings via embedding, but does so by making use of just one construction, which we argue is a complex DP embedding a relative clause. We show that this seemingly exotic syntax/semantics mapping is internally coherent and can be handled within the confines of the current syntactic and semantic theory. 
The paper is structured as follows. Section 2 presents basic information on Adyghe. Since the language is relatively unknown, we present the general information about its morphosyntax that is needed in order to follow the crucial data. Sections 3 and 4 analyze the syntax and semantics of the construction in question by looking at the cases in which it conveys the same meaning as headed and headless relative clauses in other languages. Section 5 gives an account of how the same Adyghe construction can express what embedded constituent interrogatives convey in other languages. We also show that matrix constituent interrogatives in Adyghe are actually pseudo-clefts, where one of the constituents is a DP containing a relative clause and the other constituent is made of a $w h$-word. Section 6 shows how the same Adyghe construction conveys what embedded declaratives and embedded polar interrogatives convey in other languages. Section 7 briefly looks at how Adyghe expresses what other languages encode with tensed adjunct clauses and shows that the very same construction used in the other cases is used in this case as well. Section 8 presents our overall conclusions and more general implications of our analysis.

\section{General background on Adyghe}

Adyghe is a Northwest Caucasian language spoken by approximately 500,000 people in Russia, Turkey, Iraq, and Syria (Lewis 2009). Together with Abkhaz, Abaza, Ubykh, and Kabardian, it forms the Northwest Caucasian (aka Abkhazo-Adyghe) language family (cf. Hewitt 1998, 2004). Adyghe is most closely related to Kabardian; the two languages are often called Circassian (Smeets 1984; Colarusso 1992, 2006). The language has a number of dialects; unless otherwise noted, the data in this paper are drawn from the Temirgoy dialect, which is quite close to the standard literary dialect.

Typologically, Adyghe is head-final with SOV basic word order. In matrix clauses, constituent order is relatively free. Embedded clauses, however, are typically verbfinal. Adyghe has extensive pro-drop for subjects and objects, as shown in the following naturally occurring example where the subject, direct object, and indirect object are all null pronominals.

$$
\begin{aligned}
\text { a. pro pro pro a-f-jə-ธ̌'ว-в } \\
\text { 3PL.OBL-BEN-3SG.ERG-send-PAST }
\end{aligned}
$$

'S/he sent him/her to them.'

The language uses a null copula in both identificational and specificational constructions. ${ }^{1}$

$$
\begin{aligned}
& \text { a. mə bzə } \lambda \text { fəве-r qә-sjə-thamat- } \varnothing \\
& \text { that woman-ABS DIR-1sG.POSS-director-COP } \\
& \text { 'That woman is my boss.' }
\end{aligned}
$$

\footnotetext{
${ }^{1}$ See Rogava and Keraševa (1966: 169-176, 357-358), Lander (2004), Sumbatova (2005), and Testelets (2009); see also Colarusso (1992: 53) for the null copula in Kabardian. 
b. bzə入fәве-r wәne-m daxe- $\varnothing$ woman-ABS house-OBL beauty-COP 'A woman is the ornament of a home.'

c. wəne-m daxe-r bzə $\lambda$ fәь- $\varnothing$ house-OBL beauty-ABS woman-COP 'The ornament of a home is the woman.'

In what follows, we will briefly introduce the basic morphological and syntactic properties of nominals, verbs and clauses in Adyghe that will be relevant for the subsequent discussion on relative clauses.

\subsection{Nominals}

Adyghe has a three-way morphological case system: ergative, absolutive, and oblique. $^{2}$ The absolutive marker is null, and theres is syncretism in the marking of the ergative and the oblique, as shown in (8).

(8) Adyghe case marking

\begin{tabular}{ll}
\hline Absolutive (ABS) & $-\mathrm{r}$ \\
Ergative (ERG) & $-\mathrm{m}$ \\
Oblique (OBL) & $-\mathrm{m}$ \\
\hline
\end{tabular}

The absence of case marking on a noun forces a non-specific (non-referential) interpretation of the nominal. The presence of case marking is compatible with both a specific and a non-specific interpretation. For instance, the word psa 'water' occurs without case marking in (9) and can only be interpreted as non-specific (while the whole sentence can receive a habitual or an episodic interpretation). On the other hand, if the very same word carries the marker $-r$, then it can be interpreted as either specific or non-specific, as shown in (10).

(9) se psə-Ø jə-s-e-s $\hat{\mathrm{S}}_{\mathrm{W}} \partial$

$1 \mathrm{sg}$ water LOC-1SG.ERG-PRES-drink

'I \{drink/am drinking $\}$ water.'

(10) se psə-r jə-s-e- $\hat{\mathrm{s}}_{\mathrm{W}} \partial$

$1 \mathrm{sg}$ water-ABS LOC-1SG.ERG-PRES-drink

'I \{drink/am drinking $\}$ the water.'

'I \{drink/am drinking \} water.'

Proper names, first and second person pronouns, and some kinship terms always appear without a case marker. Bare NPs without a case marker can also appear as part of a predicate, as shown by the NP č́'elejeвац̌е 'teacher' in (11), to which the silent copula that we discussed above and the future marker attach as suffixes.

\footnotetext{
${ }^{2}$ We recognize the ergative and oblique as two separate cases (cf. Rogava and Keraševa 1966; Kumakhov et al. 1996, for a similar approach). In Testelets (2009), a two-way case distinction (absolutive and oblique) is proposed, based on the identity of the ergative and oblique exponents. Whether Adyghe has a three- or two-way case distinction does not affect the main points made in our paper.
} 


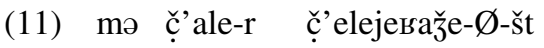

this boy-ABS teacher-COP-FUT

'This boy will be a teacher.'

First and second person pronouns do not have morphological case distinctions. Third person forms are expressed by the distal demonstrative $a$ - and exhibit the usual syncretism between ergative and oblique, as shown in (12) ( $x e$ - is the plural marker).

(12) Third person pronouns

\begin{tabular}{lll}
\hline & SINGULAR & PLURAL \\
\hline Absolutive & a-r & a-xe-r \\
Ergative & a- $\hat{\mathrm{s}}$ & a-Xe-me \\
Oblique & a- $\hat{\mathrm{s}}$ & a-xe-me \\
\hline
\end{tabular}

Demonstratives and the numeral 'one', which acts as a demonstrative, precede the noun phrase:

(13) mə he-r

this $\operatorname{dog}-\mathrm{ABS}$

(14) zə he-r

one $\operatorname{dog}-\mathrm{ABS}$

The word zə 'one' co-occurs only with DPs and can also have the reading 'only' ("one alone"). Thus, it can be used as a test for DP-hood.

If a demonstrative co-occurs with a relative clause, it normally precedes it. Relative clauses are prenominal; we will postpone their discussion until Sect. 3.

Most expressions that are used to convey what adjectives convey in languages like English exhibit morphological and syntactic properties that are typical of nouns; in fact, some researchers actually identify them as nouns (Rogava and Keraševa 1966; Smeets 1984). ${ }^{3}$ Several arguments support this position. First, the contrast between main lexical categories in Adyghe is notoriously elusive: nouns can directly combine with tense, aspect and mood markers to form predicates, and verbs can be readily nominalized. True lexical nouns can appear without an overt case marker (Lander 2004, 2005; Sumbatova 2005). ${ }^{4}$

$$
\begin{aligned}
& \text { sə- } \lambda \mathrm{e} \chi_{\mathrm{w}} \text { ○ wəne-m/wəne- } \varnothing \\
& 1 \text { sG-look_for house-OBL/house-NULL } \\
& \text { 'I am looking for a house.' }
\end{aligned}
$$

By that token, "adjectives" typically qualify as nouns because they too can appear without an over case marker (subject to dialectal variation):

\footnotetext{
${ }^{3}$ Colarusso (1992), however, puts them in a separate adjectival class.

${ }^{4}$ This pattern is robust, but we have no explanation for it. It is also attested in Austronesian languages (Broschart 1997; Himmelmann 2008), Salish (Kinkade 1983; van Eijk and Hess 1986), and Wakashan (cf. Jacobsen 1979; see also Lander and Testelets 2006, who compare Northwest Caucasian and Wakashan).
} 
(16) thamate-š $\mathrm{X}_{\mathrm{W}}-\varnothing$

director-big-NULL

'a big boss' (based on Sumbatova 2005: ex. 3)

(17) $\mathrm{k}_{\mathrm{W}} \partial-\hat{\mathrm{s}}_{\mathrm{w}} \partial-\varnothing$

cart-good-NULL

'a good cart' (Smeets 1984: 77)

Since Adyghe is head-final, the postnominal position of the "adjective" is more compatible with its status as the head noun. Rogava and Keraševa (1966: 71-77) further support the view that adjectives are actually nouns with the observation that many "true nouns" can also appear as modifiers, forming one syntactic word with the head-similar to the English compounds tile floor, coffee table, etc.

Additional criteria to identify languages without true adjectives have been proposed by Baker (2003: 246-247). These include the absence of dedicated degree words that act as functional heads, the absence of resultative secondary predication, and the absence of productive morphology that transforms nonverbal roots into stative or causative verbs (instead, such nonverbal expressions are expected to use verbs like become or make in combination with the nonverbal element). Adyghe does not have dedicated degree expressions, does not show evidence of resultatives, and frequently uses the equivalents of become or make to create stative/causative predicates with nonverbal expressions. These facts lend support to the conception that Adyghe has no true adjectives.

\subsection{Verbal morphology and clause structure}

In this section, we briefly introduce some aspects of complex verbal morphology and the basic structure of matrix declarative clauses by looking at the morphosyntactic properties of direct arguments (Sect. 2.2.1), indirect arguments (i.e. arguments licensed by applicative heads; Sect. 2.2.2), and adjuncts (Sect. 2.2.3).

\subsubsection{Direct arguments}

Adyghe verbs carry prefixes whose form depends on the case (ergative or absolutive), person, and number on their argument. ${ }^{5}$ These prefixes are presented in (18). In the dialect we are discussing here, the third person (singular or plural) absolutive prefoxes are always null. ${ }^{6}$ For simplicity, we will not show them in the glosses below unless necessary.

\footnotetext{
${ }^{5}$ See Rogava and Keraševa (1966: 135-170) and Smeets (1984: Chap. 5; Smeets 1992); see also Colarusso (1992) for Kabardian and O'Herin (2002) for Abaza.

${ }^{6}$ In some other Adyghe dialects, the third person absolutive marker is overt. For example, it is $y$-in the related Abaza (O’Herin 2002: 260) or jo/je- in Shapsug (Keraševa 1957: 69; Smeets 1984: 251).
} 
(18) Adyghe verbal prefixes

\begin{tabular}{|c|c|c|}
\hline & Absolutive (ABS) & Ergative (ERG) and Oblique (OBL) \\
\hline $1 s g$ & sə- & s-/Z- \\
\hline $2 s g$ & wว- & w-/p-/b- \\
\hline $3 s g$ & $\varnothing-$ & јə-/ว- \\
\hline $1 p l$ & tə- & $\mathrm{t}-/ \mathrm{d}-$ \\
\hline $2 p l$ & $\hat{\mathrm{s}}_{\mathrm{W}} \partial-$ & $\hat{\mathrm{s}}_{\mathrm{W}} / \hat{\mathrm{z}}_{\mathrm{W}^{-}}$ \\
\hline $3 p l$ & Ø- & a- \\
\hline
\end{tabular}

The ergative prefix precedes the root/stem, while the absolutive prefix occurs on the left edge of the verb complex. Examples illustrating these morphological patterns are in (19) and (20), with the agreement morphology boldfaced. The different order of constituents between the a. and b. examples in (19) and (20) illustrates the flexibility of word order. ${ }^{8}$
a. se axe-me s-a-š'e
1SG 3PL-ERG 1SG.ABS-3PL.ERG+PRES-lead
b. axe-me se s-a-š'e
3PL-ERG 1SG 1SG.ABS-3PL.ERG+PRES-lead
'They are leading me.'
a. č̣'ale-xe-m sabəjə-r $\quad$-a-šs'e
boy-PL-ERG child-ABS 3SG.ABS-3PL.ERG+PRES-lead
b. sabəjə-r ç̣’ale-xe-m Ø-a-š'e
child-ABS boy-PL-ERG 3SG.ABS-3PL.ERG+PRES-lead
'The boys are leading the child.'

The structure for the transitive clause in (20)a is as follows (strikethrough indicates feature checking):

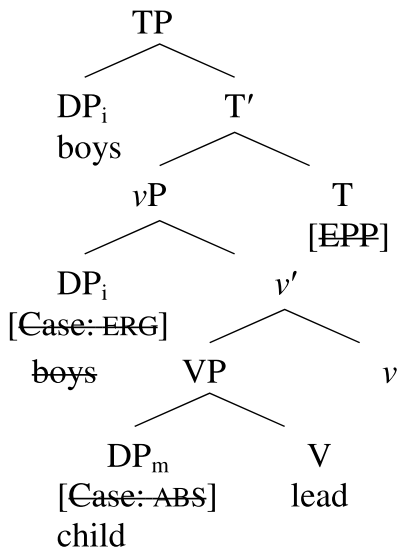

\footnotetext{
${ }^{7}$ Oblique markers are often homophonous to ergative agreement markers; they will be discussed in the next section.

${ }^{8}$ We attribute differences in word order to scrambling, but we are not committed to any particular mechanism of scrambling since nothing in our analysis hinges on it.
} 
The ergative DP is merged in the specifier of $v$, where the ergative case is also checked; the transitive $v$ serves an external theta-role assigner (Woolford 2006; Aldridge 2008; Legate 2008). This DP then moves to the specifier of T, satisfying the EPP. For the absolutive case, we assume, following Aldridge $(2004,2008)$ and Legate (2008), that its checking depends on transitivity. In a transitive clause such as the one above, the object remains in its base position inside the VP and checks its case with $v$. In an intransitive clause (not shown) the absolutive DP would have its case checked by $\mathrm{T}$.

Notice that the ergative DP c-commands the absolutive argument. There is ample evidence for this asymmetrical relation: the ergative or the absolutive subject, but not the absolutive object, can undergo subject-to-subject raising (Polinsky and Potsdam 2006; Potsdam and Polinsky 2012); the absolutive cannot bind into the ergative; the ergative is a pro-dropped argument of imperatives; the ergative is privileged under co-reference across clauses; and the ergative-absolutive configuration shows weak crossover effects (discussed in Sect. 3.2 below).

\subsubsection{Indirect arguments}

In addition to the ergative and absolutive arguments, Adyghe has indirect arguments that always appear in the generalized oblique case in $-m$ (glossed as OBL). Each indirect argument is licensed by an applicative head which is incorporated in the verb complex, and this applicative head always co-occurs with an oblique prefix (see (18) above). In the example in (22), the three elements under discussion are boldfaced and have boxes around them. The instrumental applicative head $r$ - (glossed as APPL INSTR) appears on the verb. It assigns oblique case to the DP $\hat{s}_{w}$ anə- $m$ 'hoe', and licenses the oblique verbal affix (null) which immediately precedes the applicative head itself. ${ }^{9}$ The syntactic structure we are assuming for (22) is given in (23).

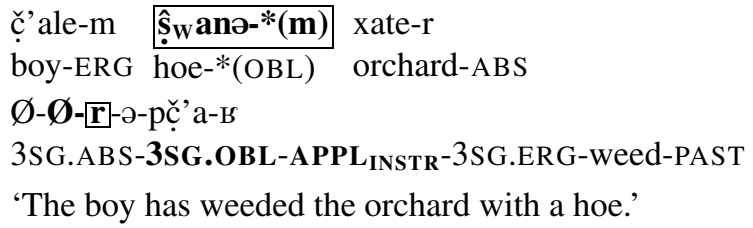

'The boy has weeded the orchard with a hoe.'

\footnotetext{
${ }^{9}$ In the glosses, we indicate all the cross-referenced arguments by their case function, so indirect arguments are glossed as oblique (OBL); their thematic role is recoverable from the meaning of the respective applicative head.
} 
(23)

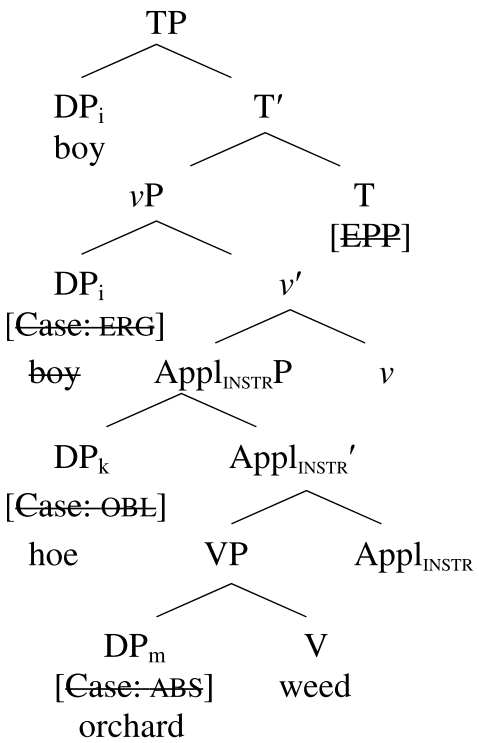

Note that unlike in Bantu, applicatives in Adyghe do not change the position or case of the base object (in the example above, it remains in the absolutive). Also, although applicatives are often limited to transitive verbs (cf. Baker 1988; Polinsky 2008; and Pylkkänen 2008 on low applicatives), in Adyghe they can combine with intransitive verbs, where they add an oblique (rather than an absolutive) argument. Depending on the dialect, Adyghe can have over a dozen such incorporated applicative heads (cf. Smeets 1984 for a detailed overview, and also Lander 2009a). The main applicative heads that will be referenced in this paper are listed in (24).

\section{(24) Applicative heads used in this paper}

\begin{tabular}{ll}
\hline Benefactive (BEN)/Motive (MOT) & $\mathrm{fe}$ \\
Comitative (COM)/Locative (LOC) & $\mathrm{de}$ \\
Locative (LOC)/Temporal (TEMP) & š'e \\
Instrumental (INSTR) & $\mathrm{r}(\partial)$ \\
Reason (REAS) & ç̌e \\
\hline
\end{tabular}

A verb form can host several indirect arguments as long as each is properly licensed by an applicative head; there does not seem to be any grammatical limit on the number of such arguments (of course, processing considerations make very heavy forms dispreferred). In the verb form, all the applicative heads precede the verbal root, and the linear order of licensing heads reflects their relative scope; the indirect argument licensed by the leftmost applicative is the highest. Thus, in (25), the leftmost applicative in the verb is the benefactive and its argument takes scope over the lower comitative object. The surface order of arguments does not change scopal relations. Notice that each applicative head prefix on the verb in (25) is immediately preceded by its oblique prefix. 
(25) zeç̌'emjə ç̣’ale-xe-m zo pŝâ̂e-m all.OBL boy-PL-OBL one girl-OBL

zə pŝâ̂e-m zeç’emjə ç’'ale-xe-m one girl-OBL all.OBL boy-PL-OBL

Ø-fə-ra-d-jə-ṣ̂ə-ь 3SG.OBL-BEN-PL.OBLCOM-3SG.ERG-make-PAST

'He made it for one girl with all the boys.'

(ONE > ALL; *ALL > ONE)

The structure for a transitive clause with applied arguments is as follows:

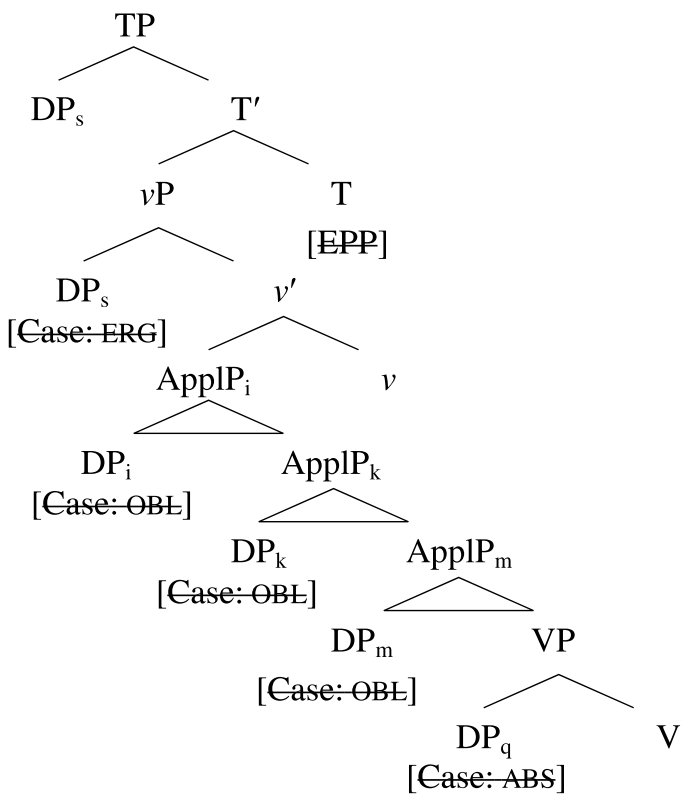

Applicatives in the related Abaza show a similar pattern of case-marking, agreement, stacking, and scope-taking (O'Herin 2001, 2002).

\subsubsection{Adjuncts}

In addition to indirect arguments, which are licensed by applicative heads, Adyghe also allows true adjuncts (Arkadiev and Letuchiy 2008). Adjunct expressions appear with one of the following suffixes or postpositions: $-\check{c}$ ' $e$ (instrumental), $-e w$ (a number of functions, including comitative), -paje 'for', azəfag ${ }_{w}$ ə 'between', әwәž'วm 'after', or in the oblique case. True adjuncts do not have an applicative host and never trigger agreement on the verb. Any adjunct can be turned into an argument by eliminating the post-position while adding the corresponding applicative head. Compare the examples in (27) and (28). In (27), the instrumental $\hat{s}_{w}$ anว-( $(m)-\check{c}$ ' $e$ (in bold and in a box) is a PP adjunct realized with the instrumental suffixal postposition - $\breve{c}^{\prime} e$ and optional oblique case marking; the instrumental applicative prefix cannot occur on the verb. In (28), instead, the instrumental $\hat{s}_{w}$ ano- $m$ (in bold and in a box) is a DP argument requiring the oblique case suffix $-m$, while the verb carries the instrumental applicative prefix $-r$ (boxed and in bold). 
(27)

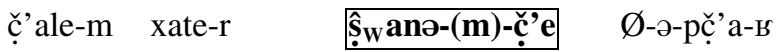

boy-ERG orchard-ABS hoe-(OBL-)-P INSTR 3SG.ABS-3SG.ERG-weed-PAST

'The boy has weeded the orchard with a hoe.'

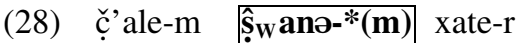

boy-ERG hoe-*(OBL) orchard-ABS

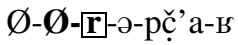

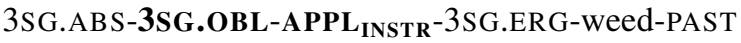

'The boy has weeded the orchard with a hoe.'

So far, our discussion has been limited to two-place verbs that take an ergative subject and an absolutive object, but there is also an extensive class of middles which take an absolutive subject and an oblique object (Smeets 1992; Arkadiev and Letuchiy 2008). In addition, the language has a distinction between so-called "dynamic" intransitive verbs, which take the prefix $e$ - located before the stem (in the word-initial position this prefix surfaces as $m e-$ ), and stative verbs, which do not form imperatives and do not combine with (m)e-(Rogava and Keraševa 1966: 104). Dynamic and stative verbs will appear in the glosses below, but their distinction does not play a significant role in our discussion.

\section{Headed relative clauses}

We can now move to the embedded construction that has a pervasive use in Adyghe and, as we show, is a relative clause. We start by looking at the one of its uses that more closely resembles relative clauses in other languages. After a description of the basic morphosyntactic features of this construction (Sect. 3.1) and a closer look at its relativizer (Sect. 3.2), we propose our syntactic and semantic analysis (Sect. 3.3).

\subsection{General description}

A relative clause in Adyghe precedes the head noun, a common pattern in headfinal languages. ${ }^{10}$ The predicate of a relative clause exhibits the same agreement, tense, and mood markers as a matrix clause predicate. Two apparent morphological differences have to do with the present tense on dynamic predicates and negation.

Dynamic predicates in the affirmative root clauses express the present tense via the dynamic prefix $(m) e$ - discussed above (29), which changes to the dynamic suffix -re when these predicates occur in a relative clause (30) or are negated:

$$
\begin{array}{ll}
\text { č'ale-r } & \text { me-k }-k_{W} \text { əwe } \\
\text { boy-ABS } & \text { DYN-yell }
\end{array}
$$

'A/The boy is screaming/yelling.'

\footnotetext{
${ }^{10}$ Adyghe also has internally-headed relative clauses, which we will not discuss; cf. Lander (2004) for their description, and Lehmann (1984) and de Vries (2002) for more general cross-linguistic patterns in relative clauses.
} 
(30) $\left[\varnothing-\mathrm{k}_{\mathrm{W}} \partial \mathrm{we}-[\mathbf{r e}-\varnothing] \quad\right.$ ç’ale-r

ABS-yell-DYN-PRES boy-ABS

'a/the boy who is screaming/yelling'

Negation in root clauses is expressed by the suffix -ep, which occurs at the right edge of the verb (31); in embedded forms (relative clauses and non-finite clauses), negation is expressed by the prefix mə- (32).

$\begin{array}{ll}\text { ç'ale-r } & \varnothing \text {-k } \mathrm{k}_{\mathrm{W}} \text { əwe-r-ep } \\ \text { boy-ABS } & \text { ABS-yell-PRES-NEG }\end{array}$

'A/The boy is not screaming/yelling.'

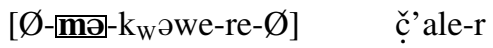

ABS-NEG-yell-DYN-PRES boy-ABS

'a/the boy who is not screaming/yelling'

Any argument of a clause (including those introduced by applicative heads) can be relativized, but only arguments can be relativized; adjuncts must first undergo applicativization (see Sect. 2.2.3 above), turning them into indirect arguments, before they can be relativized. ${ }^{11}$

In the example in (33), the three elements that are crucial for our discussion are all highlighted in boxes. The boxed NP head xate 'orchard' is preceded by the bracketed relative clause containing a boxed gap in object position (marking the missing/relativized constituent) and a related boxed absolutive marker on the verb, which is null as for regular absolutives, as already seen in (18).
[č̣’ale-m $\square \emptyset$-ə-pč̣'e-š’tə]
Xate-r
boy-ERG GAP 3SG.ABS-3SG.ERG-weed-FUT orchard-ABS
'the orchard that the boy will weed'

The bracketed relative in (33) looks superficially identical to the matrix declarative in (34), except for the position of the DP xate-r 'the orchard'. In particular, the morphological marking on the verb is the same.
č̣'ale-m xate-r
Ø-ə-pç’e-š't
boy-ERG orchard-ABS 3SG.ABS-3SG.ERG-weed-FUT
'The boy will weed the orchard.'

However, the identity illustrated above breaks down when other constituents are relativized. Any relativized argument that is not absolutive is cross-referenced on the predicate of the relative clause by the prefix $z \mathrm{~V}$ - (with $\mathrm{V}$ being $\partial, e$, or null, depending on its phonological environment). We gloss $z \mathrm{~V}$ - as the relative marker REL.X, with $\mathrm{X}$ standing for the case of the relativized argument (e.g., REL.ERG or REL.INSTR). ${ }^{12}$

\footnotetext{
${ }^{11}$ The same pattern of using applicatives as the "way station" to relativization is observed in the closely related Abaza language (O'Herin 2001, 2002).

${ }^{12}$ The relativizer $z \mathrm{~V}$ - is homophonous with at least three other verbal markers in Adyghe: indirect object agreement marker (Smeets 1984: 264), reciprocal/reflexive (Rogava and Keraševa 1966: 271-279; Smeets 1984: 267; Letuchiy 2007), and the first part of the resultative ze-re (Arkadiev and Gerassimov 2007).
} 
The position of $z \mathrm{~V}$ - in the verb form corresponds to the position of the regular agreement marker associated with that DP (we come back to this fact at the end of this section). (35) shows the relativization of an ergative argument. The relative marker appears on the verb as the prefix zə-, and as such it signals unequivocally that this is the verb of a relative clause. The corresponding matrix declarative with a non-gapped ergative DP allows for the plain 3sg ergative agreement marker ə- on the verb (36), but not for the relativizer $z \partial-(37)$.

$\begin{array}{lll}\square & \text { xate-r } & \hat{S}_{\mathrm{W}} \text { anə-m } \\ \text { GAP } & \text { orchard-ABS } & \text { hoe-OBL }\end{array}$

Ø-Ø-rə-ZZ-pč̣'e-š'tə]

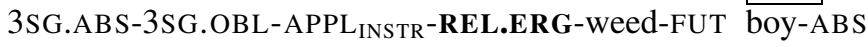

'the boy who will be weeding the orchard with a hoe'

(36) ç̣’ale-m $\hat{s}_{\mathrm{w}}$ anə-m xate-r

boy-ERG hoe-OBL orchard-ABS

$\varnothing-\varnothing-r-\mathbf{j o}-$ pč̣'e-š't ${ }^{13}$

3SG.ABS-3SG.OBL-APPL INSTR $_{\text {-3SG.ERG-weed-FUT }}$

'The boy will be weeding the orchard with a hoe.'

(37) *ç̣’ale-m $\hat{S}_{\mathrm{W}}$ anə-m xate-r

boy-ERG hoe-OBL orchard-ABS

Ø-Ø-rə-Z⿱一-pč̣'e-š’t

3SG.ABS-3SG.OBL-APPL INSTR -REL.ERG-weed-FUT

('The boy will be weeding the orchard with a hoe.')

The lack of the ergative argument within the clause in (35), the relativizer $z \mathrm{~V}$-, and the presence of the nominal head 'boy' to the right of the verb form indicate that the ergative argument underwent relativization. Note that the lack of an overt ergative argument alone would not be enough to signal relativization, since Adyghe freely allows for null pronominals in argument positions, as shown in (38).

$$
\begin{aligned}
& \text { pro } \quad \text { xate-r } \quad \text {-ә-pç̌'e-š’t } \\
& \text { (he/she) orchard-ABS 3SG.ABS-ERG-weed-FUT } \\
& \text { 'He/she will be weeding the orchard.' }
\end{aligned}
$$

As the following examples show, the relativizer marker and the applicative head can co-occur with the reciprocal ze-re-:

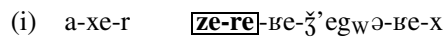

3-PL-ABS REC-APPL REC-CAUS-play-PAST-PL

'They played together.'

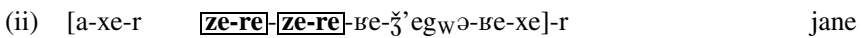

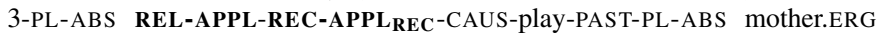

ว-? $\mathrm{w}$ a-b

3SG.ERG-Say-PAST

'The mother said that they had played together.'

${ }^{13}$ The future marker in this example and in the other matrix clause in (38) is $-\check{s}$ 't, while it is $-\check{s}^{\prime}$ to in the relative clauses in (35) and (39). This difference has nothing to do with relative $v s$. declarative clauses. Instead, the difference is due to a phonological constraint banning consonant clusters like [št $t(\#) C$ ] even across words (Smeets 1984: Chaps. 1, 2; Gordon and Applebaum 2006). 
When an argument other than an absolutive or an ergative is relativized, the relative marker occurs together with the applicative marker that usually licenses that argument. (39) shows the relativization of an instrumental. The prefix zə-appears on the verb in the same position as the instrumental agreement marker and signals that the clause is a relative clause. The instrumental prefix $r$ - and the lack of an overt instrumental within the relative clause signal that it is the instrumental argument that has been relativized (compare it with the corresponding matrix declarative in (36) above).

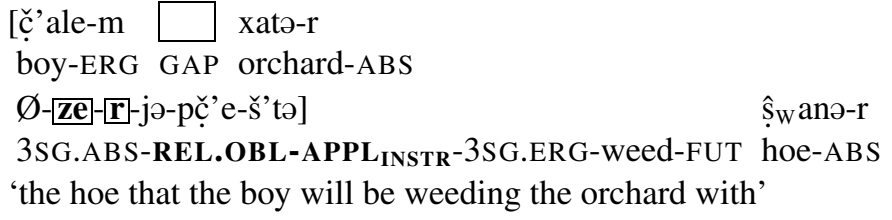

If the position of the relativizer zə- in (35) is compared with the position of the relativizer $z e$ - in (39), it becomes evident that this position varies according to the argument that is relativized. The main generalization is that the relativizer always appears in the position of the verbal agreement marker indexing the argument that undergoes relativization. Thus, in (35) the relativizer zə- occurs directly before the root (following the instrumental applicative), like the regular ergative marker $\partial$ - in the corresponding declarative in (36). In (39), the relativizer $z e$ - occurs immediately before the instrumental applicative, in the same position as the $3 \mathrm{sg}$ oblique marker $\varnothing$ in the corresponding declarative in (36). In the next section we analyze the relativizer in greater detail.

\subsection{The relativizer and its syntax}

In the previous section, we saw that the Adyghe construction that we are investigating can be used as a relative clause; the verbal morphology on that clause marks the missing/gapped/relativized constituent. No special overt marking on the verb is observed if the gap is in the absolutive. If the gap corresponds to any other argument, then what we called the relativizer $z \mathrm{~V}$ - occurs on the verb in the same position as the agreement marker in the corresponding matrix declarative clause without the gap. What exactly is this relativizer, and what is its function? If the construction in which it occurs is a relative clause, what is the syntactic structure of Adyghe relative clauses?

Our proposal is as follows: all the embedded clauses that we have encountered so far are relative clauses. All relative clauses in Adyghe have a relativizer; it is null (Ø-) in a relative clause with an absolutive gap, and it is $z \mathrm{~V}$ - in all the other relative clauses. The relativizer occurs in the position of the corresponding agreement marker on the verb and phonologically merges with (or possibly replaces) the existing marker. ${ }^{14}$ Semantically, it introduces a variable that must be bound by a c-commanding moved

\footnotetext{
${ }^{14}$ The distribution of the relativizer in Adyghe is similar to Abaza (O'Herin 2002: Chap. 8) and Kabardian (Colarusso 1992: 189, 191-193). O'Herin (2002) also makes a point of comparing and contrasting the Northwest Caucasian wh-agreement marker ('relativizer' in our terminology) with the Austronesian pattern proposed for Chamorro (Chung 1998) or Malagasy (Pearson 2005). We concur that the two phenomena are distinct and refer the reader to O'Herin's discussion for details.
} 
operator (in SpecC of the relative clause), as shown in (40). The details of our semantic proposal will be discussed in the next section.

(40) $\left[\mathrm{CP} \mathrm{Op}_{1}\left[\mathrm{TP} \mathrm{e}_{1}\right]\right]$

Three classes of phenomena support our proposal: island effects, possessive marking, and weak crossover effects. The first argument is that a headed relative clause is syntactically an island, and we will show this by demonstrating that it is impossible to extract out of the relative clause, while it is possible to extract out of a simple DP. We start by proving that headed relative clauses are syntactic islands. Example (41) shows a simple declarative. We see that the relativization of the subject of (41) is possible (42a), but if we try to extract the object out of the latter, the result is unacceptable (42b). Similarly, the relativization of the object of (41) is possible, as shown in (43a), but from (43a) nothing can be extracted, as shown by the unacceptability of the extraction of the subject in (43b). Henceforth, we indicate the gap with the empty category symbol e. In the examples immediately below, the head of the relative clause and the associated gap and relativizer are all co-indexed for clarity and the relevant gap and the corresponding relativizer are in bold and in a box as well.

ç̣'ale-xe-m pjəsme-r $\varnothing$-a-txə-Ь

boy-PL-ERG letter-ABS 3SG.ABS-3PL.ERG-write-PAST

'The boys wrote a/the letter.'

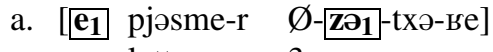
č́ale-xe-r 1
letter-ABS 3SG.ABS-REL.ERG-write-PAST boy-PL-ABS
'the boys that wrote a/the letter'

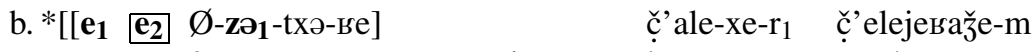
3SG.ABS-REL.ERG-write-PAST boy-PL-ABS teacher-ERG
$\begin{array}{ll}\emptyset_{2}-\text {-ə- } \lambda \text { ев }{ }_{\mathrm{W}} \text { ə-ве] } & \text { pjəsme-r } \\ \text { REL.ABS-3SG.ERG-see-PAST } & \text { letter-ABS }\end{array}$
'the letter that the teacher saw the boys that wrote'
a. [č́’ale-xe-m $\mathbf{e}_{\mathbf{1}} \boldsymbol{\emptyset}_{\mathbf{1}}$-a-txə-вe] pjəsme-r ${ }_{1}$
boy-PL-ERG REL.ABS-3PL.ERG-write-PAST letter-ABS
'the letter that the boys wrote'

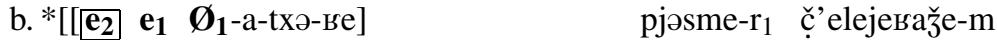
REL.ABS-3PL.ERG-write-PAST letter-ABS teacher-ERG

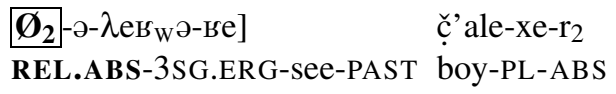

'the boys that the teacher saw the letter that wrote'

The ban on extraction out of headed relative clauses cannot be due to their being embedded within a DP, since Adyghe allows extraction out of a DP, as the following examples show. ${ }^{15}$ (44) provides an example of a complex DP containing the head nominal 'clusters' and another nominal 'strawberry' acting as a modifier. (45a,b) show that the modifying nominal can be extracted out of the DP-the predicate occurs between the two nominals.

\footnotetext{
${ }^{15}$ See Gerasimov and Lander (2008) for the same observation with further supporting examples.
} 
(44) [DP a $c_{\text {W}}$ ompe ?erame-xe-r] daxe- $\emptyset$-x that strawberry cluster-PL-ABS be_beautiful-PRES-PL
a. [DP a $\mathbf{t}_{\mathbf{1}}{ }^{2}$ erame-xe-r] daxe- $\varnothing$-x
$\mathrm{c}_{\mathrm{W}} \mathrm{mmpe}_{1}$ that cluster-PL-ABS be_beautiful-PRES-PL strawberry
b. $\mathrm{c}_{\mathrm{W}}{ }^{2}$ [DPe ${ }_{1}$ daxe- $\varnothing-\mathrm{x}$ a $\mathbf{t}_{1}$ 'erame-xe-r] strawberry be_beautiful-PRES-PL that cluster-PL-ABS 'Those strawberry clusters look beautiful.'

(46) contains another complex DP, in which the nominal head 'voice' is modified by 'angry' and also includes the possessive 'girls'. (47) shows that the nominal head 'voice' can be extracted out of the DP and moved to its right. (48) shows that the modifier 'angry' can be extracted as well, though not all our consultants accepted it. Finally, (49) shows that the nominal 'voice' can be extracted and moved to the left to the DP as well, as demonstrated by the temporal 'in the morning' occurring in between it and the DP.

(46) [DP pŝâ̂e-me ja-g ${ }_{\mathrm{w}}$ əbžəве maqe-xe-r ] qe ${ }_{\text {wə-ь }}$ girl-OBL.PL 3PL.POSS-angry voice-PL-ABS sound-PAST

'One could hear the girls' angry voices.' (Rogava and Keraševa 1966: 381)

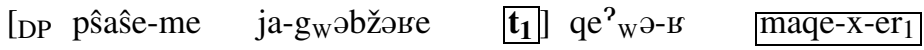

$$
\begin{aligned}
& \text { girl-OBL.PL 3PL.POSS-angry sound-PAST voice-PL-ABS }
\end{aligned}
$$

'One could hear the girls' angry voices.'

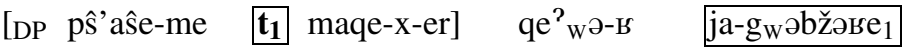

$$
\begin{aligned}
& \text { girl-OBL.PL voice-PL-ABS sound-PAST 3PL.POSS-angry }
\end{aligned}
$$

$$
\begin{aligned}
& \text { maqe-X-er } \left.1 \text { pčedəž’om [DP pŝaŝe-me ja-g } \text { w }_{\text {w }} \text { bžəвe } \mathbf{t}_{1}\right] \\
& \text { voice-PL-ABS in_the_morning girl-OBL 3PL.POSS-angry } \\
& \mathrm{qe}^{\text {? }}{ }_{\text {W }} \mathrm{-B} \\
& \text { sound-PAST } \\
& \text { 'In the morning one could hear the girls' angry voices.' }
\end{aligned}
$$

The next piece of evidence in favor of a structural analysis of the Adyghe construction as a relative clause comes from possessive marking (Lander 2009b). The absolutive DP argument of the declarative clause in (50) (the "possessee") carries the $3 \mathrm{pl}$ marker ja- (the "possessor"), which can be co-indexed with the ergative DP or with an arbitrary discourse antecedent; the boys can but do not need to be the possessor of the car.

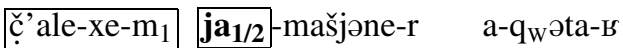

$$
\begin{aligned}
& \text { boy-PL-ERG 3PL.POSS-car-ABS 3PL.ERG-break-PAST } \\
& \text { 'The boys }{ }_{1} \text { broke their }{ }_{1 / 2} \text { car.' }
\end{aligned}
$$

If the ergative DP argument in (50) is relativized, two options are available for possessive marking. One option is to use the possessive marker $j a$ - with its usual interpretative properties (co-indexed with the head of the relative or free), as shown in 
(51). The other option is to replace the possessive marker ja-with the marker $z \mathrm{~V}$-, as shown in (52); we gloss this marker as POSS.REL. In the case of (52), the only available interpretation is obligatory coindexation with the head of the relative: the boys must be the possessor of the car.

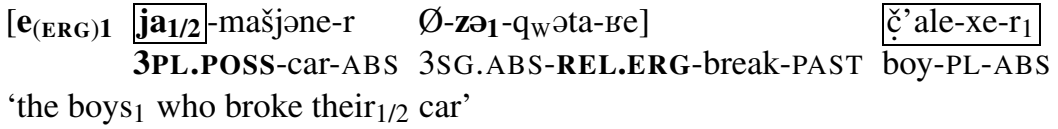

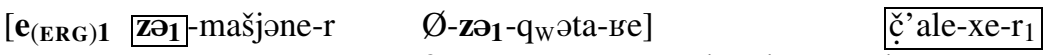

$$
\begin{aligned}
& \text { POSS.REL-car-ABS 3SG.ABS-REL.ERG-break-PAST boy-PL-ABS } \\
& \text { 'the boys } 1 \text { who broke their } 1 /{ }^{2} \text { car' }
\end{aligned}
$$

The same pattern is found in the construction that is interpreted as an embedded constituent interrogative, which we show to be a relative clause as well in Sect. 5.1. On the other hand, the possessive agreement marker $z \mathrm{~V}$ - cannot appear in root clauses. If the possessive marker $j a$ - in the root clause in (50) above is replaced with the possessive marker $z \partial^{-}$, the result is ungrammatical:

$$
\begin{array}{cll}
* \text { *č'ale-xe-m } & \text { ZO1-mašjəne-r } & \text { a-qwəta-B } \\
\text { boy-PL-ERG } & \text { POSS.REL-car-ABS } & \text { 3PL.ERG-break-PAST }
\end{array}
$$

The marker $z \mathrm{~V}$ - cannot appear under A-movement either-it is impossible in raising constructions, which instantiate A-movement (cf. Polinsky and Potsdam 2006; Potsdam and Polinsky 2011 for the details of this construction). (54) shows the raised version of (50) with an aspectual verb as the matrix predicate, and the marker $z \mathrm{~V}$ replacing the possessive prefix ja-. The result is judged unacceptable.

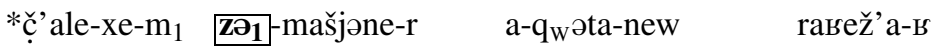

$$
\begin{aligned}
& \text { boy-PL-ERG POSS.REL-car-ABS 3PL.ERG-break-INF begin-PAST }
\end{aligned}
$$

The appearance of the possessive marker $z \mathrm{~V}$ - is thus limited to relative clauses and signals that the possessor is co-indexed with the relativized/gapped constituent. Following O'Herin (2002: 270-275), who documents a similar pattern in Abaza, we identify the use of $z \mathrm{~V}$ - in possessors inside relative clauses as an instance of agreement with the $w h$-trace. This phenomenon exhibits properties typical of agreement: it is strictly local, and the agreeing element cannot be structurally higher than the possessor. Crucially, this possessive agreement marker cannot appear in a matrix clause or in any clause where A-bar movement has not taken place, so it is sensitive to the presence of a trace of movement and shares its $w h$-feature under coreference (see also O'Herin 2002: 264-265). In conclusion, the presence of the possessive $z \mathrm{~V}$ - can be taken as further evidence in favor of our analysis of the Adyghe construction as a relative/A-bar construction.

In the last argument we present, we again make use of possessive constructions in order to show that relative clauses in Adyghe exhibit weak crossover, as is typical of constructions with a moved operator. We start with the construction in (55), in which the absolutive object is relativized and the ergative subject carries the $3 \mathrm{SG}$ possessive prefix -jo. The possessive prefix can be co-indexed with an arbitrary antecedent or with the nominal head of the relative (though the latter option is dispreferred). If 
the possessive marker is replaced with the relativizer possessive prefix $z \mathrm{~V}-$, the coindexed interpretation is unacceptable, as shown in (56). ${ }^{16}$ Our proposal can account for this restriction since the possessive marker $z \mathrm{~V}$ - intervenes between the lower trace of the gapped absolutive argument and its c-commanding operator, a typical weak crossover configuration. Notice that the relative possessive marker $z \mathrm{~V}$ was allowed in (52) above, where the ergative subject was relativized and was c-commanding the possessive $z \mathrm{~V}$ - occurring on the absolutive object. The unacceptability of (56) is particularly striking given that weak crossover is usually further weakened in relative clauses (Lasnik and Stowell 1991). ${ }^{17}$

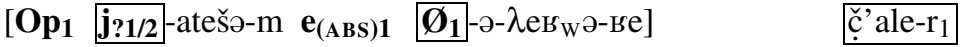

$$
\begin{aligned}
& \text { 3SG.POSS-uncle-ERG REL.ABS-3SG.ERG-see-PAST boy-ABS }
\end{aligned}
$$

'the boy 1 that his ${ }_{\text {?1/2 }}$ uncle saw'

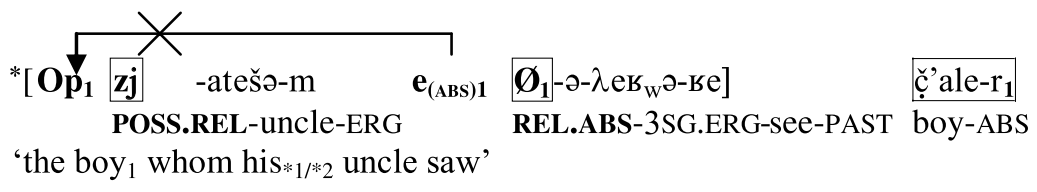

To sum up, island effects, possessive marking, and weak crossover effects further support our proposal that the Adyghe construction we are investigating is a relative clause containing an operator that binds its trace. This construction no longer looks like an exotic, mysterious phenomenon, but rather like an uncontroversial syntactic structure found in many languages: a headed relative clause. Its semantic behavior is also quite straightforward, as we show in the next section.

\subsection{Semantic analysis of headed relatives}

The sentence in (57) contains a bracketed complex DP embedding a headed relative whose syntactic structure and semantic derivation are given in (58). For the sake of simplicity, we henceforth omit the TP projection and various applicative projections between the $\mathrm{CP}$ and the $v \mathrm{P}$ in all our trees unless they prove necessary for our discussion. Also, the syntactic nodes that are semantically inert are not numbered in the trees and are ignored in the semantic derivations.

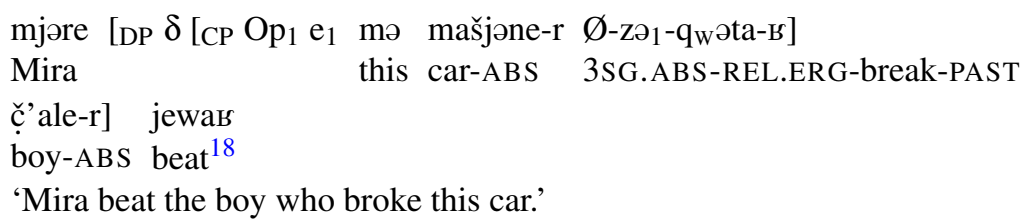

\footnotetext{
${ }^{16}$ The interpretation 'the boy whom someone else's uncle saw' is impossible because the DP 'uncle' is case marked. If it appeared without a case marker, as is possible for possessive groups, the latter interpretation would become available (see Lander 2009b: ex. 38 for such an example). This interpretation is, however, irrelevant for the points made here.

${ }^{17}$ There is no evidence that Adyghe licenses parasitic gaps, which makes another standard argument for a moved operator unavailable.

${ }^{18} \mathrm{We}$ omit the morphological analysis of the matrix predicate since it is not directly relevant to our discussion.
} 


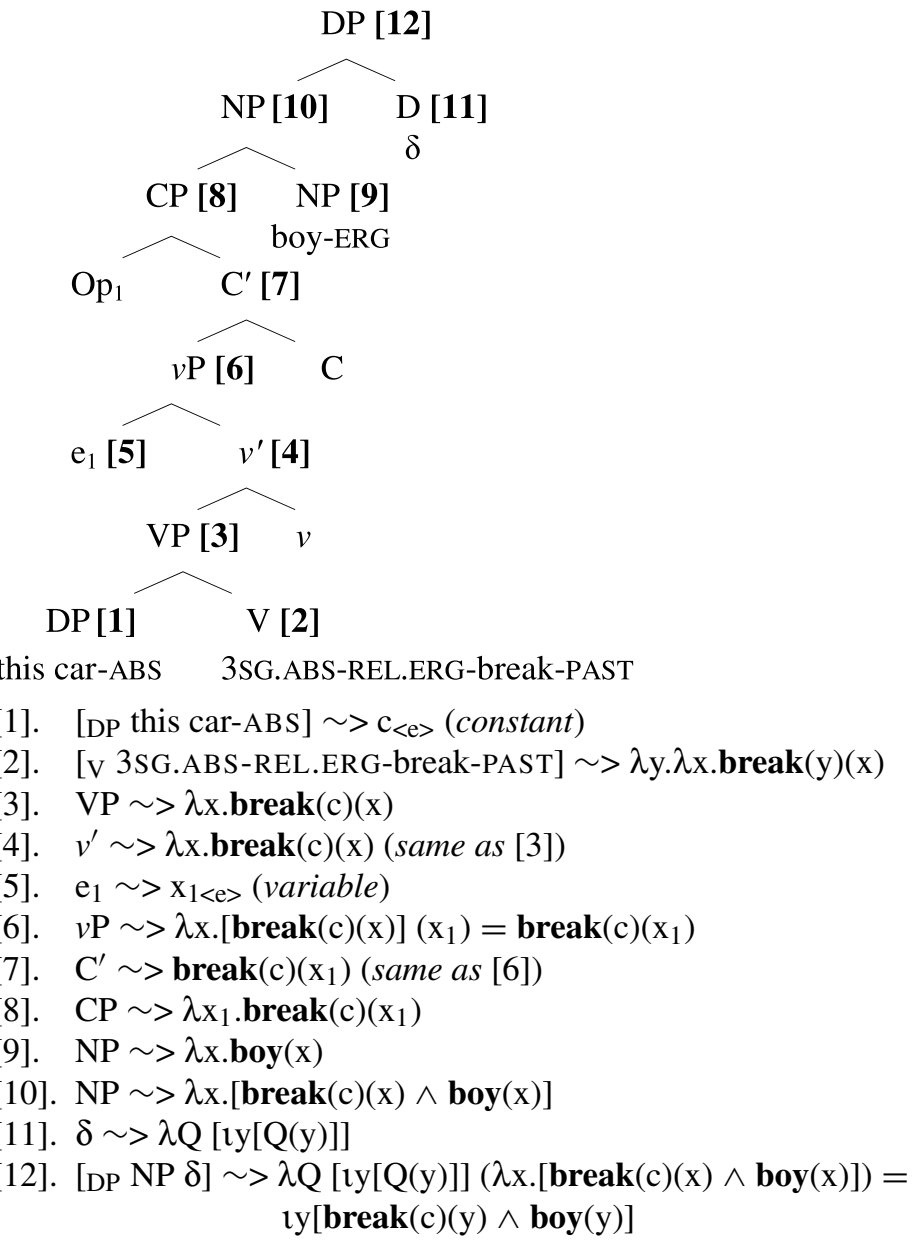

In the derivation in (58) (as in all the others to follow), we ignore the semantic import of tense (cf. step [2]); also, we translate referential DPs into individual constants without further analyzing them, unless relevant for the discussion (cf. step [1]). We assume that the gap $\left(\mathrm{e}_{1}\right)$ in a headed relative translates into a variable $\mathrm{x}_{1}$ ranging over individuals (step [5]), which combines with the predicate first (step [6]) and is then bound by the operator Op $\mathrm{p}_{1}$ via lambda-abstraction (step [8]). The whole CP ends up denoting a set of individuals, which is the standard denotation of a restrictive relative clause. As discussed earlier, the operator $\mathrm{Op}_{1}$ is licensed by the verbal morphology, i.e. the ergative relativizer zə- in (57)-(58). The set of individuals the CP denotes (step [8]) combines with the set of individuals the nominal head denotes (step [9]) by standard predicate modification (Quine 1960; Montague 1973). The resulting set (step [10]) is turned into its maximal individual by the maximalization operation (step [12]). This operation can be implemented by means of a type-shifting rule in the semantics or a silent maximality operator $\delta$ in the syntactic structure. We choose the latter and assume the operator $\delta$ to be the D head of the DP containing the relative CP (step [11]). Partee (1986), Chierchia (1998), and 
Dayal (2004) independently argue for this operation in accounting for the semantic behavior of certain NPs/DPs, while Jacobson (1995) and Caponigro (2004) make a similar point for free/headless relatives.

Nouns can be interpreted specifically/maximally or non-specifically/nonmaximally also when modified by relative clauses, as shown in (59). The intensional matrix predicate and the optative marker on the embedded predicate in (59) strongly favor the non-specific interpretation of the complex nominal containing the relative clause. In the favored reading, it is not even presupposed that there are people who know Chinese.

$$
\text { [kjətajə-bze zə-ṣ̂e-g } \left.{ }_{\mathrm{w}} \partial-\mathrm{re}\right] \quad \text { cəfə-m sə- } \lambda \mathrm{e} \chi_{\mathrm{w}} \mathrm{e}
$$

Chinese-language REL.ERG-know-POT-PRES person-OBL 1SG.ABS-look

'I am looking for someone who knows Chinese.' (non-specific reading)

'I am looking for the person/people who know(s) Chinese.' (specific reading)

The semantic proposal above accounts only for the dispreferred specific reading in (59): the maximality operator $\delta$ applies to the set of individuals that know Chinese and returns a unique (atomic or plural) maximal one, i.e., the person/people who are contextually salient and know Chinese. Therefore, the preferred non-nonspecific reading in (59) must result from a different process. One option is that intensional predicates like 'look for' select for a property-denoting complement, rather than an individual-denoting one (cf. Zimmermann 1993). The complex nominal containing the relative clause could then combine directly with the intensional predicate without any further operation, since its basic denotation is a set of individuals (cf. (58): step [8]), whose intension is a property. Whatever the correct account for the nonspecific reading is, it would be an option that is independently needed in the grammar of Adyghe in order to handle the more general problem of the interpretation of nominals. In fact, non-specific readings are found with simple nominals as well, and not just in the construction under discussion (cf. Sect. 2.1: ex. (9) and (10) and related discussion).

In conclusion, we have shown that the Adyghe construction conveying what a headed relative conveys in other languages is actually a headed relative clause syntactically and semantically, despite the superficial differences. These differences are mainly due to the rich Adyghe verbal morphology, with a complex system of verbal agreement and a relativizer that marks the argument that undergoes relativization. In the next section, we show that relative clauses in Adyghe can be used without a nominal head.

\section{Headless relative clauses}

\subsection{Morphosyntactic structure of headless relatives}

Adyghe headless relative clauses are morphosyntactically identical to the headed relatives we just discussed: they have the same tense and agreement marking on the verb, and the same relativizer signaling which argument has been relativized. The predicate in the headless relative in (60) and the predicate in the headed relative in (61) are identical except for their rightmost suffix. 
(60)

$\left[e_{1}\right.$ xate-r $\quad$ -

orchard-ABS 3SG.ABS-REL.ERG-weed-FUT-*(ABS)

'the one/some who will weed the orchard'
$\left[\mathrm{e}_{1}\right.$ xate-r
Ø-zə1-pč̣’e-š’tə](*-r)
ç’ale(-r)
orchard-ABS 3SG.ABS-REL.ERG-weed-FUT- $(*$ ABS) boy-ABS
'the/a boy who will weed the orchard'

The headless relative must have the absolutive case marker on its predicate, and this case marker must appear as the rightmost suffix (60). On the other hand, the headed relative cannot have the case marker on its predicate, but only (and optionally) on its nominal head (61). When the head lacks overt case marking only the non-specific interpretation is available. On the other hand, when overt case marking occurs, either the specific or the non-specific interpretation is available, depending on the context. For example, the intensional matrix predicate and the optative marker on the embedded predicate in (62) below strongly favor the non-specific interpretation of the headless relative in complement position.
[kjətajə-bze
zə-ṣ̂e-g $\left.g_{W} \partial-r e\right]-m$
sə- $\lambda \mathrm{e} \chi_{w} \mathrm{e}$

Chinese-language REL.ERG-know-POT-PRES-OBL 1SG.ABS-look

'I am looking for someone who knows Chinese.' (non-specific reading)

'I am looking for the one/person who knows Chinese.' (specific reading)

Headless relatives, like their headed counterparts, are islands for extraction. (63) shows an example of a headless relative with a relativized ergative subject and an overt absolutive object (we highlight the gap and the associated relativizer in bold, in boxes, and by co-indexation). If the absolutive object is extracted by further relativization, as shown in (64), then the resulting string is completely unacceptable.

[е

letter-ABS 3SG.ABS-REL.ERG-write-PAST-OBL

'the one that wrote a/the letter'

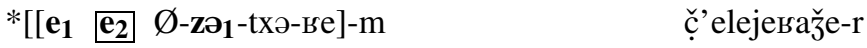

$$
\begin{aligned}
& \text { 3SG.ABS-REL.ERG-write-PAST-OBL teacher-ABS } \\
& \varnothing-\mathbf{Z \boldsymbol { O } _ { 2 }}-\lambda \text { е } \chi_{\mathrm{w}}{ } \text {-ве ] }
\end{aligned}
$$

3SG.ABS-REL.OBL-look-PAST letter-ABS

('a/the letter that the teacher was looking for the one that wrote it')

Headless relatives, therefore, can receive the same syntactic analysis as proposed for the headed relative clause:

\section{(65) $\left[\mathrm{CP} \mathrm{Op}_{1}\left[\mathrm{TP} \mathrm{e}_{1}\right]\right]$}

A question that arises at this point is what the structure above the headless relative clause may be. There are at least two possibilities: a headless relative could be just a headed relative with a null NP as its head (66), or it could consist of a D head that directly takes a CP complement (66). In what follows, we assume (66) for the sake of simplicity. ${ }^{19}$ Nothing hinges on this assumption, and evidence in favor of one

\footnotetext{
${ }^{19}$ Cf. Groos and van Riemsdijk (1981) a.o. for the null-head analysis, Caponigro (2002) a.o. for the D-head analysis, and van Riemsdijk (2005) for an overview of the syntax of free relatives.
} 
analysis or the other is hard to come by, given that many traditional properties that identify the category 'noun' do not hold in Adyghe.
a. [DP [NP [CP Op $\left.\left.\left.1\left[\mathrm{TP}_{1}\right]\right][\mathrm{N} \varnothing]\right] \mathrm{D}\right]$
b. [DP [CP Op $\left.1 ~\left[T P ~ e_{1}\right]\right]$ D]

Putting aside the details of the syntax of Adyghe headless relatives, we can conclude that they look very similar to headed relatives in Adyghe. In the next section, we give a detailed syntactic structure and semantic derivation for headless relatives in order to show how their meaning can be derived by standard compositional mechanisms that have already been invoked for other constructions and/or languages.

\subsection{Semantic analysis of headless relatives}

The bracketed string in (67) is the headless relative corresponding to the headed relative we discussed earlier (Sect. 3.3: (57)-(58)). The only difference is that the relative in (67) lacks a nominal head and has the absolutive marker $-r$ occurring as a suffix on its predicate rather than on a nominal head. The syntactic structure and the complete semantic derivation for the example in (67) are given in (68).
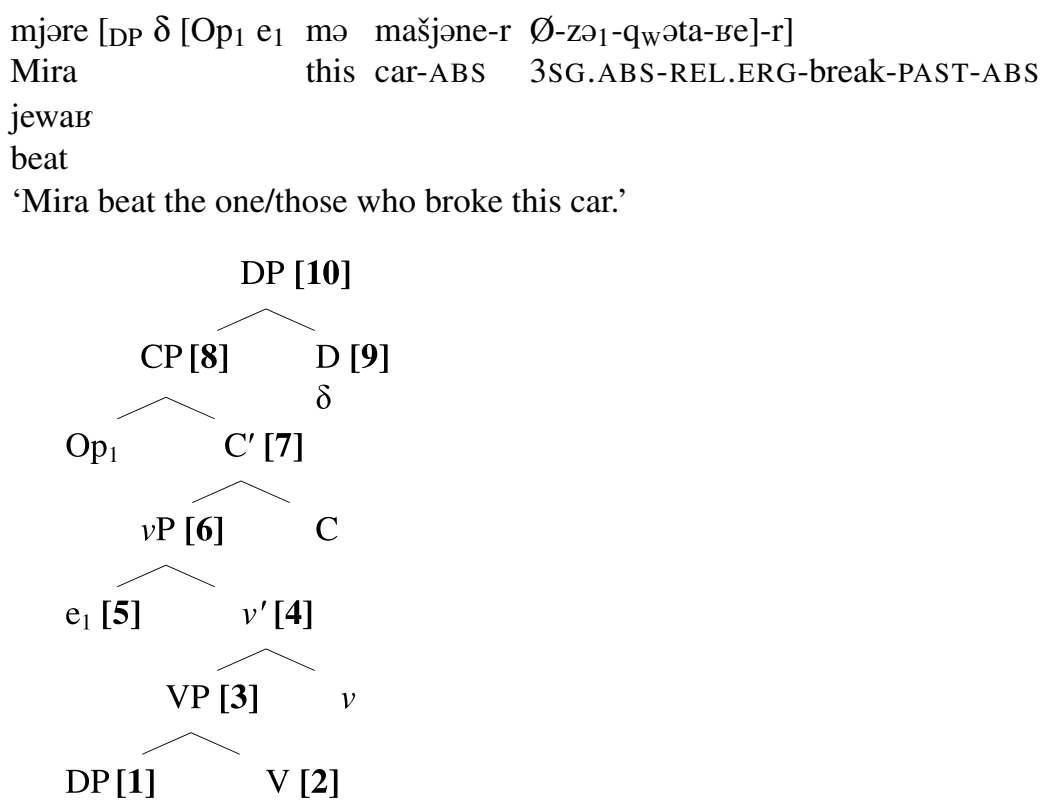

this car-ABS 3SG.ABS-REL.ERG-break-PAST

[1]-[8]. Same as the interpretation of the headed relative clause in (58): $[1]-[8]$

[9]. $\delta \sim>\lambda \mathrm{Q}[\mathrm{ly}[\mathrm{Q}(\mathrm{y})]]$ (same as in (58): [9])

[10]. $\quad[\mathrm{DP} C \mathrm{CP} \delta] \sim>\mathrm{Q}[\mathrm{ty}[\mathrm{Q}(\mathrm{y})]]\left(\lambda \mathrm{x}_{1} \cdot\left[\operatorname{break}(\mathrm{c})\left(\mathrm{x}_{1}\right)\right]\right)=\operatorname{ty}[\operatorname{break}(\mathrm{c})(\mathrm{y})]$

The syntactic structure and the semantic derivation in (68) are almost identical to those of the headed relative (57)-(58). The only syntactic difference is the absence of 
a nominal head in (68), where the D head directly takes the CP as its complement. Semantically, the set of individuals the $\mathrm{CP}$ ends up denoting does not intersect with the set denoted by the nominal head, since the latter is missing (or semantically inert, if a null head analysis of headless relatives is adopted). Maximalization applies directly to the set of individuals denoted by the $\mathrm{CP}$ and turns it into its maximal individual.

In (62), we saw that headless relatives in the complement position of an intensional predicate can receive two readings: a non-specific one (which is preferred) and a specific/maximal one. We have already observed the same ambiguity in simple nominals (Sect. 2.1: example (10)) and headed relatives (Sect. 3.3: example (59)). All these constructions are set-denoting DPs to which maximalization usually applies, turning them into individual-denoting expressions. Therefore, whatever mechanism accounts for the ambiguity in simple nominals and headed relatives (see the discussion in Sect. 3.3) applies to free relatives as well.

To summarize, this section and Sect. 3 have investigated how Adyghe conveys what other languages convey by means of headed or headless relatives and found that Adyghe uses the same basic construction. Like standard relatives across other languages, the Adyghe construction is a $\mathrm{CP}$ with an operator binding a variable/gap. Unlike other languages, it does not have an overt $w h$-word, a relative pronoun, or a complementizer. A special relativizer (zə- or $\emptyset$-), instead, occurs as a prefix on the verb and marks the argument that has been relativized. The whole $\mathrm{CP}$ is adjoined to a nominal head (headed relative) or occurs as the complement of a D head (headless relative). In conclusion, Adyghe turns out to be less exotic than it appeared at first glance: it has relative clauses and they are rather standard both syntactically and semantically, despite their striking morphological make-up. In the next sections, we will see that Adyghe uses relative clauses to convey a number of other meanings typically associated with different constructions in other languages.

\section{Constituent interrogatives: matrix and "embedded"}

In this section, we investigate the construction that Adyghe uses to encode what other languages convey by means of constituent interrogatives clauses. We will see that Adyghe does not have standard embedded interrogatives, which is why "embedded" appears in quotation marks in the section title. Instead, as we show in Sect. 5.1, Adyghe makes use of headless relatives to convey the meaning typically associated with embedded interrogatives. We provide a compositional semantic account for this structure by appealing to the concealed question strategy, which has been independently argued for in other constructions and/or languages (Sect. 5.2). Finally, we examine matrix constituent interrogatives and conclude that they are pseudo-clefts consisting of a headless relative preceding or following a null copula and a $w h$-word (Sect. 5.3). ${ }^{20}$

\footnotetext{
${ }^{20}$ In what follows, we focus on the core interpretation of Adyghe interrogatives, since it is sufficient for our purposes, and do not investigate the tangential issue of the availability of other interpretations (e.g., functional readings, pair-list readings, etc.).
} 


\section{1 "Embedded constituent interrogatives"}

Adyghe uses two different strategies to convey what an embedded constituent interrogative conveys in other languages; neither resembles standard embedded constituent interrogatives. One is the headless relative clause just discussed. The other is direct quotation, which doesn't make use of actual embedding (cf. Rogava and Keraševa 1966: 395-397; Sumbatova 2005). In what follows, we discuss the first strategy only, since it is the one that is relevant for our investigation of embedding in Adyghe.

The bracketed clause in (69) is almost identical to the headless relative in (67) above: it has the same overt relativizer prefix zə- marking the ergative gap and an obligatory case marking suffix. The suffix is the oblique $-m$ (rather than the absolutive $-r$ in (67)) because of the different case assignment properties of the matrix verbs. The interpretation of the bracketed clause in (69), though, is different from the interpretation of the bracketed clause in (67). In particular, the bracketed clause in (69) no longer denotes an individual, but rather is interpreted as an English-style embedded constituent interrogative, as shown by the translation.

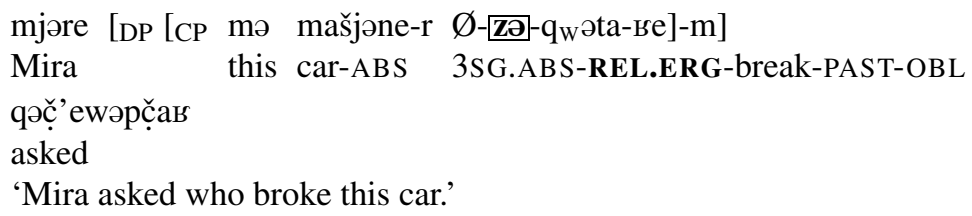

If Mira's question is instead about the object of 'break', then the headless relative looks as it does in (70). The only difference with (69) is the presence of a null relativizer (the difference in the case marking follows from the case-assigning properties of the matrix verb).

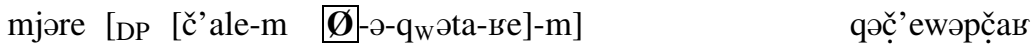

$$
\begin{aligned}
& \text { Mira boy-ERG REL.ABS-3SG.ERG-break-PAST-OBL asked } \\
& \text { 'Mira asked what the boy broke.' }
\end{aligned}
$$

"Embedded constituent interrogatives" questioning other constituents are also formed on the basis of headless relatives, as shown in (71) for the comitative argument.

$$
\begin{aligned}
& \text { mjəre [DP [CP č’alem mə mašjəner } \\
& \text { Mira boy.ERG this car.ABS }
\end{aligned}
$$

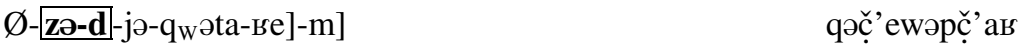

$$
\begin{aligned}
& \text { 3SG.ABS-REL.OBL-APPL } \text { COM } \text {-3SG.ERG-break-PAST-OBL asked } \\
& \text { 'Mira asked with whom the boy broke this car.' }
\end{aligned}
$$

Just as was the case for headed and headless relative clauses, the constructions expressing embedded constituent interrogatives are syntactic islands. (72) shows that if the absolutive object in (71) is extracted out of its clause, the result is unacceptable.

(72) *mə mašjəner mjəre [DP [CP č’ale-m

$$
\text { this car.ABS Mira boy-ERG }
$$

$\varnothing$-zə-d-jə-q qə⿳̆冖' ewəpc̣̆as

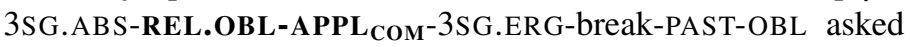

('Mira asked, this car, with whom the boy broke.') 
Notice that the same interrogative predicate that takes the headless relative as its complement in the examples above can take a plain DP complement as well, to which it still assigns oblique case, marked by the usual suffix $-m$ (73). This shows that the selectional properties of an interrogative predicate like Adyghe 'ask' are compatible with our previous conclusion that headless relatives in Adyghe are DPs and with our current hypothesis that headless relative can occur as complements of interrogative predicates.

$$
\begin{aligned}
& \text { [DP sə-çe] qəc̣̆'ewəpč̣as } \\
& \text { 1SG.POSS-name asked }
\end{aligned}
$$

To sum up, Adyghe clausal complements of interrogative predicates are headless relative clauses, rather than embedded constituent interrogatives.

\subsection{Semantics of "embedded constituent interrogatives"}

Having concluded that the clausal complement of interrogative predicates in Adyghe is a headless relative, the semantic analysis discussed earlier (Sect. 4.2) should apply in this case as well (at least, this should be the default hypothesis), and thus the headless relative should end up denoting an individual. This poses a problem, however; the interrogative predicate looks for a clausal complement denoting a set of propositions, leading to a type mismatch. This mismatch is reminiscent of the situation with "concealed questions".

Concealed questions are DPs denoting individuals, names, or numerical values that can occur as the complement of interrogative predicates and can be interpreted as embedded interrogatives. For instance, the DP the capital of France denotes an individual (a certain city in France), but in the sentence Tell me [the capital of France], the same DP is interpreted as the bracketed embedded constituent interrogative in Tell me [what the capital of France is]. Similarly, the DP the price denotes a certain numerical value (or an individual concept from worlds to numerical values), but it can also occur as the complement of the interrogative predicate ask as in She asked me [the price] and can be interpreted in the same way as the bracketed embedded constituent interrogative in She asked me [what the price was]. Adyghe has true concealed questions too, as shown by the bracketed DPs in (74)-(77) and their interpretations (see also ex. (73) above).

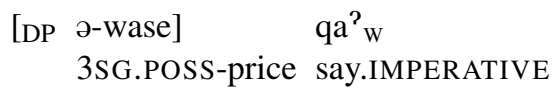

'Say how much this costs.' (Lit.: 'Say its price.')

[DP mə səhatə-r] s-ṣ̂e-r-ep

this hour-ABS 1SG-know-PRES-NEG

'I don't know what time it is.' (Lit.: 'I don't know the hour.')

$$
\begin{aligned}
& \text { [DP } \left.\boldsymbol{B}_{\mathrm{W}} \mathrm{eg}_{\mathrm{w}} \partial-\mathrm{r}\right] \mathrm{q} \partial-\mathrm{s}-\mathrm{a}-{ }^{2}{ }_{\mathrm{w}} \text { etež }{ }^{2} \text {-r-ep } \\
& \text { road-ABS DIR-1SG.OBL-3PL.ERG-retell-PRES-NEG }
\end{aligned}
$$

'They would not tell me how to get there.' (Lit.: '... tell me the road.') 
(77) [DP sša-m jə-prezjədent(*-ər)] w-e-ṣ̂-a?

USA-OBL POSS-president-ABS 2SG-PRES-know-INTERR

'Do you know who is the president of the USA?' (Lit.: 'Do you know the president...')

We suggest that the same mechanism that allows speakers of Adyghe and other languages to interpret plain DPs in the complement position of an interrogative predicate as embedded constituent interrogatives is at work in Adyghe when a headless relative occurs as the complement of an interrogative predicate. We exemplify our proposal by discussing the example in (69), repeated below as (78). We propose the semantic derivation in (79) for the complex DP containing a headless relative that occurs as the complement of the interrogative predicate.

$$
\begin{aligned}
& \text { mjəre [DP Op } \mathrm{p}_{C Q} \delta\left[\mathrm{CP}_{\mathrm{Cp}} \mathrm{Op}_{1} \mathrm{e}_{1}\right. \text { mə mašjəne-r } \\
& \text { Mira } \\
& \text { this car-ABS }
\end{aligned}
$$

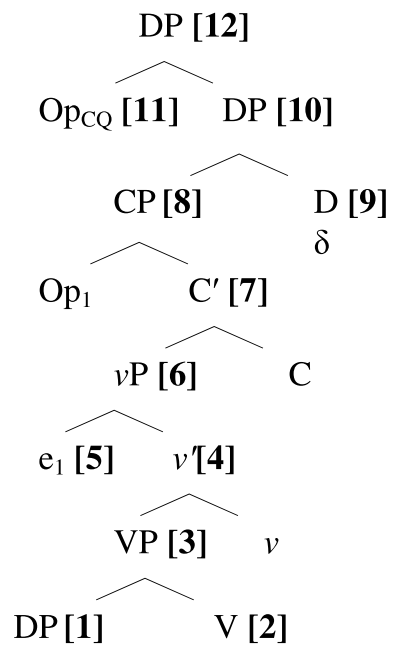

this car-ABS 3SG.ABS-REL.ERG-break-PAST

[1]-[10]: Same as the interpretation of the headless relative in (68): [1]-[10]

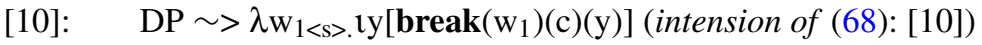

[11]. $\quad \mathrm{Op}_{\mathrm{CQ}} \sim>\lambda \mathrm{x}_{<\mathrm{se}>} . \lambda \mathrm{p}_{<\mathrm{st}} .[\exists \mathrm{y}[\mathrm{p}=\lambda \mathrm{w}[\mathrm{y}=\mathrm{x}(\mathrm{w})]]$

[12]. $\quad[\mathrm{DP}$ OpcQ DP] $\sim$

$$
\begin{aligned}
& \lambda \mathrm{x} \cdot \lambda \mathrm{p}\left[\exists \mathrm{y}[\mathrm{p}=\lambda \mathrm{w}[\mathrm{y}=\mathrm{x}(\mathrm{w})]]\left(\lambda \mathrm{w}_{1} . \mathrm{ty}\left[\operatorname{break}\left(\mathrm{w}_{1}\right)(\mathrm{c})(\mathrm{y})\right]\right)=\right. \\
& \lambda \mathrm{p}[\exists \mathrm{y}[\mathrm{p}=\lambda \mathrm{w} \cdot[\mathrm{y}=\mathrm{ty}[\operatorname{break}(\mathrm{w})(\mathrm{c})(\mathrm{y})]]
\end{aligned}
$$

In the semantic derivation in (79) above, we assume that the interrogative predicate licenses a concealed question operator ( $\mathrm{Op}_{\mathrm{CQ}}$ in [11]) that takes the intension of its complement (the individual concept in [10]) and returns an identity question, i.e., a set of propositions [12]. The choice of $\mathrm{Op}_{\mathrm{CQ}}$ is just for the sake of simplicity and presentational purposes. The semantic contribution of OpcQ could easily be 
incorporated into the lexical semantics of the interrogative predicate; alternatively, other type-shifting operations could be postulated. The specific details of the semantic analysis of concealed questions have been at the center of an ongoing debate, recently enriched with several contributions (Heim 1979; Frana 2006; Nathan 2006; Romero 2006; Caponigro and Heller 2007). As far as we can tell, any of the current proposed solutions would be compatible with our analysis.

It has been observed that the nature of the nominal within a DP plays a role in the availability of a concealed question interpretation for that DP. In particular, nouns like price, name, weight, score, etc. can more easily trigger a concealed question interpretation than non-functional nouns (cf. Nathan 2006; Romero 2006; Caponigro and Heller 2007, a.o.).

Also, Nathan (2006) and Caponigro and Heller (2007: ex. 51) note that a relative clause can facilitate the concealed question interpretation of DPs containing a nonfunctional noun. For instance, compare (80a) and (80b) (Nathan 2006: 116, ex. 70a and 71a, respectively). The main predicate of both sentences is tell, which selects for an expression denoting a proposition or a set of propositions in its complement position. In both cases, tell takes an individual denoting DP containing the non-functional noun semanticist as its complement. A concealed question interpretation of the DP complement is needed in order for the sentences to be acceptable. In (80a), semanticist is modified by the genitive USNDH's and the sentence is judged awkward. In (80b), semanticist is modified by a relative clause with virtually the same semantic content as the genitive and the acceptability of the sentence improves.

a. \#Tell me [DP USNDH's semanticist].

b. Tell me [DP the semanticist who teaches at USNDH].

If Nathan's (2006) generalization is correct, it would support our proposal that a concealed question interpretation is always available with headless relatives in Adyghe. To be more precise, headless relatives always lack the potential obstacle to a concealed question interpretation, namely a nominal of the wrong semantic kind, since they do not have a (contentful) nominal head at all. On the other hand, headless relatives always include an element that facilitates a concealed question interpretation, namely a relative clause (since they are relative clauses according to our analysis).

To summarize so far, we have shown that Adyghe uses headless relatives to express what other languages convey with embedded constituent interrogatives - these headless relatives are interpreted as concealed questions. Before concluding, let's take a quick look at how Adyghe forms matrix constituent interrogatives.

\subsection{Matrix constituent interrogatives}

Example (81) shows a matrix constituent interrogative clause questioning its object, while (82) shows how the subject of the clause is questioned.

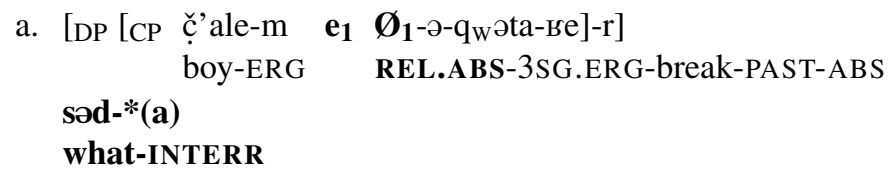




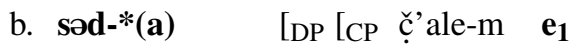
what-INTERR boy-ERG

$\emptyset_{1-\partial-q w \partial t a-\text {-re]-r] }}$

REL.ABS-3SG.ERG-break-PAST-ABS

'What did the boy break?' (Lit. 'What is the thing the boy broke?')

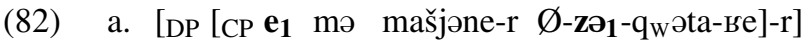

this car-ABS 3SG.ABS-REL.ERG-break-PAST-ABS

xet-*(a)

who-INTERR

b. xet-*(a) [DP [CP $\mathbf{e}_{1}$ mə mašjəne-r

who-INTERR this car-ABS

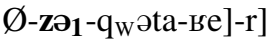

3SG.ABS-REL.ERG-break-PAST-ABS

'Who broke this car?' (Lit. 'Who is the one/person who broke this car?')

In both (81) and (82), the appropriate wh-word must occur and carry the interrogative marker $-a$ (glossed INTERR) as its suffix (this suffix also appears on matrix polar interrogatives, and we will return to it in the discussion of embedded polar interrogatives below). As the examples in (81) and (82) show, the wh-word can occur sentence-initially or finally. In these examples, the bracketed constituent looks like the headless relatives we have been discussing: they exhibit the same relativizer on the verb ( $\varnothing-$ or $z ə-)$ and the same absolutive case marker as the rightmost suffix on the verb (-r). This is why we bracket the strings in (81) and (82) as DPs containing a $\mathrm{CP}$, as we did for headless relatives earlier.

Examples of matrix constituent interrogatives questioning constituents other than subjects and objects are given in (83)-(86) below. In each example, the wh-word and the interrogative marker are required and can occur optionally at the end of the sentence.

$$
\begin{array}{llll}
\begin{array}{l}
\text { tod-a } \\
\text { where-INTERR }
\end{array} & {[D P[C P} & \text { a-r } & \mathbf{e}_{\mathbf{1}} \\
\text { 3SG-ABS }
\end{array}
$$

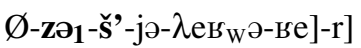

3SG.ABS-REL.OBL-APPL LOC -3SG.OBL-See-PAST-ABS

'Where did she see him/her?' (Lit. 'Where is the place s/he saw him/her (at)?')

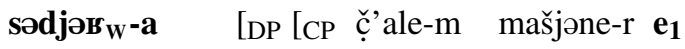

$$
\begin{aligned}
& \text { when-INTERR boy-ERG car-ABS }
\end{aligned}
$$

3SG.ABS-REL.OBL-APPL TEMP-3SG.ERG-break-PAST-ABS

'When did the boy break the car?' (Lit. 'When is it that the boy broke the car?')

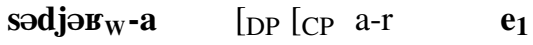

$$
\begin{aligned}
& \text { when-INTERR 3SG-ABS }
\end{aligned}
$$

3SG.ABS-REL.OBL-happen-PAST-ABS

'When did this happen?' (Lit. 'When is it that this happened?') 
(86)
səd-a
what-INTERR
[DP [CP $\mathbf{e}_{1}$ wə-z-č́' e-k $\left.\left.\mathrm{K}_{\mathrm{W}} \partial w e-r e\right]-r\right]$
2SG-REL.OBL-APPL REAS-yell-PRES-ABS

'Why are you screaming?' (Lit. 'What is [the reason] that you are screaming for?')

Notice that (84) and (85) illustrate two different ways of questioning a temporal constituent, either with both the relativizer and the temporal applicative prefix on the verb (84) or just with the relativizer but without the applicative prefix (85). ${ }^{21}$

The entire matrix constituent interrogative in Adyghe is therefore composed of a $w h$-word and a headless relative. Recall that Adyghe has a silent copula (Sect. 2, ex. (7)). We suggest that this silent copula connects the two constituents, as highlighted by our literal translations above. The construction is syntactically a pseudocleft with the $w h$-word behaving like a syntactic predicate, with the interrogative marker attached to it, and the headless relative behaving like the subject, as schematized in $(87 \mathrm{a}, \mathrm{b}) .^{22}$

\section{(87) Structure of matrix constituent interrogatives in Adyghe}

a. [[wh-word+INTERR $]_{\text {PRED }}[$ silent $\mathrm{COP}] \underbrace{\left[\mathrm{DP}\left[\mathrm{CP} \mathrm{Op}_{1}\left[\mathrm{TP}_{1}\right]\right] \mathrm{D}\right.}_{\text {HEADLESS RELATIVE }}]_{\mathrm{SUBJ}}]$

b. $[\underbrace{\left[\mathrm{DP}\left[\mathrm{CP} \mathrm{Op}_{1}\left[\mathrm{TP}_{1}\right]\right] \mathrm{D}\right.}_{\text {HEADLESS RELATIVE }}]_{\text {SUBJ }}[$ silent $\left.\mathrm{COP}][w h \text {-word+INTERR }]_{\mathrm{PRED}}\right]$

This pattern of question formation is widely attested cross-linguistically (den Dikken et al. 2000; Potsdam 2007, 2009; Potsdam and Polinsky 2011; a.o.). A semantic analysis for the structures in $(87 \mathrm{a}, \mathrm{b})$ is not directly relevant for our purposes-what really matters to us is that relative clauses are used in matrix constituent interrogatives as well. Nevertheless, such an analysis can be implemented straightforwardly along the line of Jacobson's (1994) and Sharvit's (1999) proposals on identity of copular constructions and pseudo-clefts: our headless relative ends up denoting an individual, the $w h$-word translates into a variable ranging over individuals, and the identity copula requires its two arguments to refer to the same individual.

The hypothesis schematized in (87) receives further support from the fact that the $w h$-word can be replaced by a referential DP so that the whole clause is turned into an uncontroversial identity statement. For instance, the declarative clause in (88) is an identity statement; it is almost the same as the interrogative clause we already saw in (81), the only difference being that (88) has a DP instead of a wh-word.

\footnotetext{
${ }^{21}$ This phenomenon is reminiscent of those temporal DPs that are interpreted as PPs even without an overt preposition in English and other languages (e.g. It happened (on) [DP that day]/[DP Monday]) (Larson 1985; McCawley 1988; Caponigro and Pearl 2009, a.o.).

${ }^{22} \mathrm{~A}$ detailed analysis of this construction as a pseudo-cleft (as opposed to a cleft) is beyond the scope of this paper. In brief, the arguments for it being a pseudo-cleft are as follows: first, the wh-word directly combines with the interrogative marker, as expected if it is part of the predicate rather than (part of) the clefted constituent. Second, the $w h$-word does not form a constituent with the headless relative. Third, the headless relative is syntactically a DP (which is compatible with being a pseudo-cleft) and not just a bare CP (which is what the non-clefted constituent in a cleft is). Finally, the whole construction exhibits connectivity effects, like pseudo-clefts. See Sumbatova (2009) for further discussion.
} 


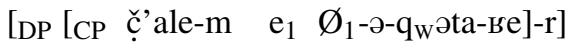

$$
\begin{aligned}
& \text { boy-ERG 3SG.ABS-3SG.ERG-break-PAST-ABS } \\
& \text { w-jə-mašjəna- } \\
& \text { 2SG-POSS-car-PAST }
\end{aligned}
$$

A matrix constituent interrogative, crucially, can never be embedded as such in Adyghe. As we saw in the previous section, headless relatives are used to convey what embedded interrogatives convey in other languages. In other words, only the subject DP in (87) can be embedded, but not the whole structure with a $w h$-word, regardless of the order or presence of the interrogative marker $-a$, as shown in $(89 a, b)$.

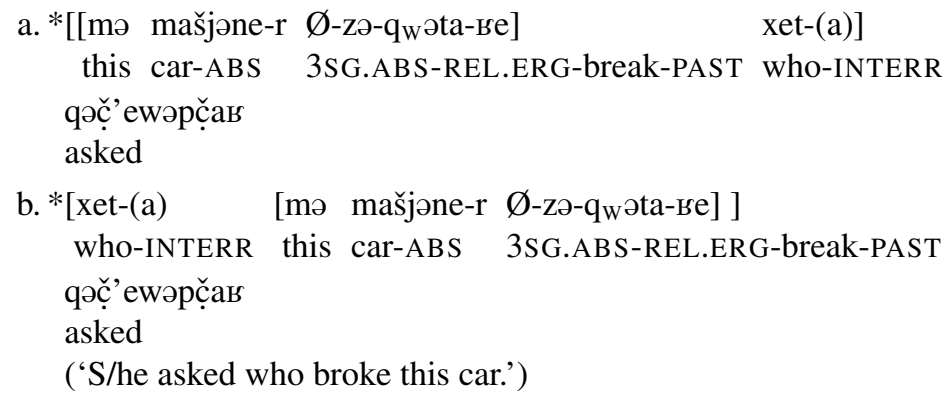

Incidentally, unlike English, multiple wh-words are impossible in Adyghe, both in matrix and in embedded interrogatives. An equivalent of the English multiple whinterrogative in (90) is achieved by coordinating single $w h$-interrogatives, as shown in (91). Notice that no pair-list reading is available in (91) for Adyghe, unlike the English (90).

(90) Mira asked [who broke what].

$$
\begin{aligned}
& \text { mjəre [DP [CP } \left.\left.\varnothing \text {-zə-q }{ }_{w} \partial t a-\text {-se }\right]-m\right]-j ə \\
& \text { Mira 3SG.ABS-REL.ERG-break-PAST-OBL-and } \\
& \text { [DP [CP Ø---qwəta-se]-m]-jə qәč̣' ewəpč̣as } \\
& \text { REL.ABS-3SG.ERG-break-PAST-OBL-and asked }
\end{aligned}
$$

To sum up, although Adyghe has a mechanism for constructing matrix constituent interrogatives with $w h$-words and an interrogative marker, the entire matrix constituent interrogative cannot be embedded. Instead, Adyghe uses complex DPs containing a headless relative that lacks both the $w h$-word and the interrogative marker to convey what embedded constituent interrogatives convey in a language like English. In the next sections, we will see that there is much more that Adyghe can convey by means of its DPs containing relative clauses.

\section{Declaratives and polar interrogatives: matrix and "embedded"}

In this section, we investigate the Adyghe strategy of expressing what other languages convey by means of declaratives and polar interrogatives. In Sect. 6.1, we briefly discuss matrix declaratives and matrix polar interrogatives in Adyghe. In Sect. 6.2, we 
show that Adyghe does not have anything that resembles familiar embedded declaratives or embedded polar interrogatives. Instead, the language again uses relative clauses. In Sect. 6.3, we propose a compositional semantic analysis that derives both meanings. In Sect. 6.4, we briefly touch on the similarities between Adyghe and more familiar languages that our analysis highlights, making Adyghe look less exotic than it may seem at first glance. Finally, Sect. 6.5 discusses and rejects an analysis according to which embedded declaratives and polar interrogatives have homophonous complementizers that surface as verbal prefixes.

\subsection{Matrix declaratives and matrix polar interrogatives}

Examples $(92 \mathrm{a}, \mathrm{b})$ show examples of matrix declaratives in Adyghe with the noun č'ale-r 'boy' behaving as the subject (as signaled by the case marker $-r$ ) and the noun $\check{c}^{\prime}$ 'elejевац̌e 'teacher' behaving as the predicate (as signaled by the lack of case marking and the presence of a silent copula with the future suffix - $\check{t} t$ ). The two sentences differ only in word order. Examples $(93 \mathrm{a}, \mathrm{b})$ show the corresponding matrix polar interrogatives. The only difference between matrix declaratives and matrix polar interrogatives is the already familiar interrogative marker - $a$, which appears at the right edge of the predicate of interrogative clauses, regardless of the surface position of the predicate (cf. (93a) and (93b)). The matrix declarative in (94) and the matrix polar interrogatives in $(95 \mathrm{a}, \mathrm{b})$ exemplify the same pattern but with an overt transitive predicate.

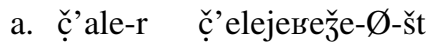

Matrix declarative boy-ABS teacher-COP-FUT

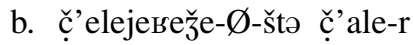
teacher-COP-FUT boy-ABS

'The boy will be a teacher.'

a. ̣̌’ale-r ç̣̆'elejeseže- $\varnothing$-št-[a]?

boy-ABS teacher-COP-FUT-INTERR

Matrix polar interrogative

b. ç̣’'elejeвеže- Ø-št-a teacher-COP-FUT-INTERR boy-ABS

'Will the boy be a teacher?'

č̣’ale-m mə mašjəne-r $\varnothing$-ə-q w $_{\text {}}$ ta-в boy-ERG this car-ABS 3SG.ABS-3SG.ERG-break-PAST

'The boy broke this car.'

a. č̣’ale-m mə mašjəne-r ə- $\mathrm{q}_{\mathrm{w}} \partial \mathrm{ta}-\mathrm{-}-\mathbf{a}$ ? Matrix polar interrogative boy-ERG this car-ABS 3SG.ERG-break-PAST-INTERR

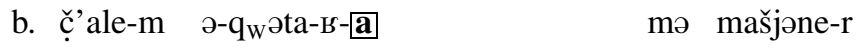
boy-ERG 3SG.ERG-break-PAST-INTERR this car-ABS

'Did the boy break this car?' 


\section{2 "Embedded declaratives" and "polar interrogatives"}

We now turn to the Adyghe equivalent of embedded declaratives or embedded polar interrogatives. Neither matrix declarative nor matrix interrogative clauses can be embedded. Example (96) shows an attempt to embed the matrix declarative in (94), while (97) shows the attempted embedding of the matrix polar interrogative in (95) (with and without the interrogative marker). Neither is acceptable.

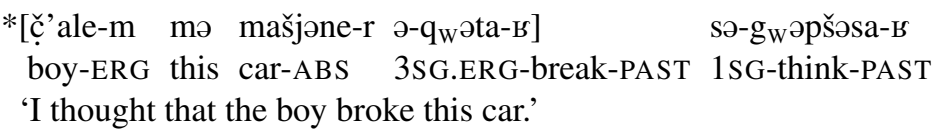

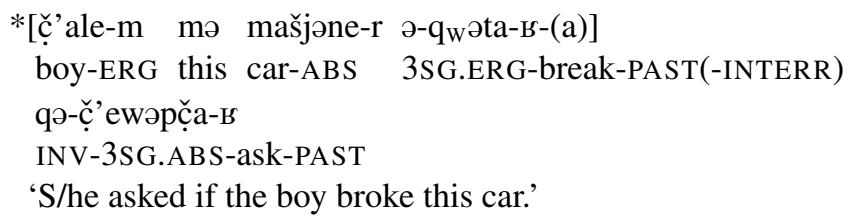

To express an embedded clause, a DP containing a relative clause has to be used. Such a DP occurs as the complement of a propositional attitude predicate like 'think' (98) or as the complement of an interrogative predicate like 'ask' (99).

$$
\begin{aligned}
& \text { [DP [CP č̣’ale-m mə mašine-r } \\
& \text { boy-ERG this car-ABS }
\end{aligned}
$$

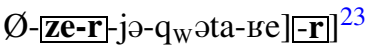

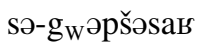

3SG.ABS-REL.OBL-APPL-3SG.ERG-break-PAST-ABS 1SG-thought 'I thought that the boy broke this car.'

$$
\begin{array}{r}
\text { [DP [CP č́ale-m mə mašine-r } \\
\text { boy-ERG this car-ABS }
\end{array}
$$

$\emptyset$-ze-r-j-jə-q qə⿳̆’ ewวpс̣̌as

3SG.ABS-REL.OBL-APPL-3SG.ERG-break-PAST-OBL asked

'S/he asked if the boy broke this car.'

We know the bracketed strings are DPs in (98) and (99) above because of the case marker suffix at their right edge (shown in boldface and boxed). That they are DPs containing a relative $\mathrm{CP}$ is apparent from the fact that the embedded verb carries the relativizer $z e$ - (in boldface, boxed). Notice that the two DPs in (98) and (99) are identical, except for the case marker, which depends on the different case assigning properties of the respective main predicate.

A further piece of evidence supports the identity of the two bracketed constructions in (98) and (99). Consider the predicate 'know' in English; it can take both declarative and interrogative complements (100). The Adyghe equivalent of 'know' takes only a DP with a relative clause attached, but that DP can receive two different interpretations, corresponding to the declarative and the interrogative readings in English (101).

\footnotetext{
${ }^{23}$ When the applicative prefix $r e$ - is followed by the 3 sg ergative agreement marker ${ }^{-}$, the sequence is realized as $r$-jo (Smeets 1984: 3.2, 4.7).
} 
(100) a. She doesn't know [CP that Marina lives here].

b. She doesn't know [CP if Marina lives here].

(101) [DP[CP marjəne məš' Ø-ze-re-š’ว-psewว-re]-r]

Marina here 3SG.ABS-REL.OBL-APPL-LOC-live-PRES-ABS

a-š' $\quad$-ṣ̂̂e-r-ep

3SG-ERG 3SG-know-pres-NEG

'S/he does not know that Marina lives here.'

'S/he does not know whether Marina lives here.'

Also, both embedding predicates in the sentences above can take uncontroversial plain DPs as their complements (102)-(103), which further supports our analysis of "embedded clausal complements" as DPs.

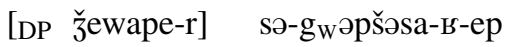

answer-ABS 1SG-think-PAST-NEG

'I could not think of an answer.'

$$
\begin{array}{lll}
\text { [DP } & \text { sə-çe } & \text { qəç̌’ewəpc̣̆as } \\
& \text { 1sG.POSS-name asked }
\end{array}
$$

'S/he asked my name.'

Finally, both clausal complements in (98) and (99) are strong syntactic islands. (104)-(106) show that the bolded constituents in boxes cannot scramble out of the clauses, which is true for any constituent in headed and headless relatives, cf. (42)(43) and (63)-(64), respectively.

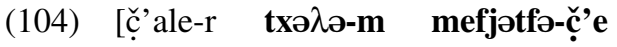
boy-ABS book-OBL 5_days-PINSTR

Ø-ze-r-je-ža-se-r] marjəne jeṣ̂e $\mathrm{e}^{24}$

3SG.ABS-REL.OBL-APPL-3SG.OBL-read-PAST-ABS Marina knows

'Marina knows that the boy read the book in five days.'

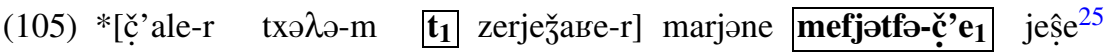
boy-ABS book-OBL read-ABS Marina 5_days-PINSTR knows

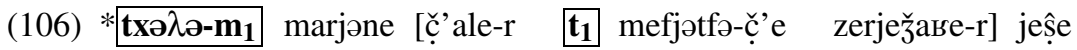
book-OBL Marina boy-ABS 5_days-P INSTR read-ABS knows

\subsection{Semantics for "embedded polar interrogatives" and "embedded declaratives"}

In the previous section, we established that Adyghe does not have embedded declaratives or embedded polar interrogatives (this explains the quotation marks in the section headings). It uses the same kind of complex DP containing a relative clause to convey what embedded declaratives and embedded polar interrogatives convey in

\footnotetext{
${ }^{24}$ The embedded clause is based on an example from Arkadjev and Letuchiy (2008: Example 22).

${ }^{25}$ The glosses of Examples (105) and (106) have been simplified for readability. See Example (104) for detailed glosses.
} 
other languages. What distinguishes this kind of relative clause from the other relatives we have seen so far is the verbal prefix re-, which looks like a prefixal applicative marker. This marker occurs higher on the verb than any other applicative, as shown in (107a). Unlike the other applicative markers, which can change their relative order, it cannot follow any other applicative, as shown in (107b). ${ }^{26}$ For these examples, recall that the applicative prefix licencing the relativized argument is always immediately preceded by the relativizer $z e-$.

a. Ze-re- Ø-fə-ra-de-s-ṣ̂a-se-r

REL.OBL-APPL-3SG.OBL-BEN-3PL.OBL-COM-1SG.ERG-do-PAST-ABS 'that I did that for him/her with them'

b. * $\varnothing$-fə-Ze-r-a-de-s-ṣ̂a-se-r

3SG.OBL-BEN-REL.OBL-APPL-3PL.OBL-COM-1SG.ERG-do-PAST-ABS

Like all relatives, the relatives in (98) and (99) instantiate an operator-variable configuration, as signaled by the relativizer prefix $z e$ - and the applicative prefix $r e-$. They are also syntactically opaque (they are islands). Their variable, though, ranges over a different kind of semantic object than the variables we have discussed so far, as signaled by the high applicative verbal prefix re-, which distinguishes them from the other relative clauses. We suggest this variable ranges over polarity operators.

A polarity operator is a function that takes a proposition $\mathrm{p}$ and returns either the very same proposition $p$ (the positive polarity operator, $f_{P O S}: \lambda p . p$ ) or its negation $\sim p$ (the negative polarity operator, $f_{\mathrm{NEG}}: \lambda \mathrm{p} . \sim \mathrm{p}$ ). Therefore, the entire headless relative ends up denoting a set containing the two polar operators $\left\{f_{\mathrm{POS}}, \mathrm{f}_{\mathrm{NEG}}\right\}$ (shortcut for $\{\lambda$ p.p, $\lambda$ p. $\sim$ p $\})$ after standard lambda abstraction over the variable has applied.

Polar operators and variables over them have been independently argued for to account for scope interactions within polar interrogatives in English and other languages (Guerzoni 2004; Romero and Han 2004). The intuition that we want to capture by appealing to polar operators is that embedded declaratives and embedded polar interrogatives share a basic feature at the level of their semantic contribution: their denotations are built on the same proposition.

For instance, the denotations of the embedded declarative (that) Mary left and of the embedded polar interrogative if/whether Mary left in English both depend on the proposition 'that Mary left'. This proposition is either the actual denotation of the clause, as in the case of the embedded declarative, or, together with its complement/negation, occurs as a member of a set of propositions, as in the case of the embedded polar interrogative (i.e., \{that Mary left, that Mary didn't leave $\}$ ).

According to our proposal so far, the semantic contributions of the relative clauses in (98) and (99) are the same: they both denote the set $\left\{f_{\mathrm{POS}}, \mathrm{f}_{\mathrm{NEG}}\right\}$, or, equivalently, $\{\lambda$ p.p, $\lambda$ p. $\sim$ p $\}$. On the other hand, the matrix predicates 'think' in (98) and 'ask' in

\footnotetext{
${ }^{26}$ See the discussion of applicatives in Adyghe in Sect. 2.2.2 above. See also Gerasimov and Lander (2008) and Lander (2009a, 2009b), who analyze re- in this construction as an applicative marker. In particular, Gerasimov and Lander (2008) analyze this re-as an instrumental applicative. We believe there are at least two reasons not to follow their proposal. First, the applicative in our construction and the instrumental applicative are phonologically distinct: our applicative is always $r e-$, while the instrumental applicative marker is $r 2$-. Second, the two applicatives can co-occur (see footnote 12).
} 
(99) are usually assumed to select for different semantic objects: the propositional attitude predicate 'think' selects for a proposition, while the interrogative predicate 'ask' selects for a set of propositions.

One option in addressing this semantic mismatch is to stipulate that the lexical meanings of propositional attitude and interrogative predicates in Adyghe are different from their counterparts in languages like English. Specifically, in Adyghe both kinds of predicates would select for a set of polarity operators in Adyghe, but would impose different truth conditions. ${ }^{27}$ This possibility is hard to rule out but it is also difficult to substantiate-we have been unable to observe any independent special properties of Adyghe verbal lexicon that would support this approach.

We would like to pursue an alternative approach here and reduce this kind of complex DP containing a relative clause (i.e., complex DPs conveying what embedded declaratives or polar interrogatives convey in other languages) to another relative construction in Adyghe. We start by looking at the case in which the complex DP occurs as the complement of a propositional attitude predicate and is interpreted as an embedded declarative is in other languages. (108) exhibits such an example. Interestingly, our consultants judge (109) and (110) as truth-conditionally equivalent to (108), despite the structural differences. (109) and (110) contain the same relative clause as in (108), except now the relative clause is immediately followed by a nominal head meaning 'news' or 'validity/verity/truth' (in bold and boxes in the examples below), which hosts the case marker suffix.

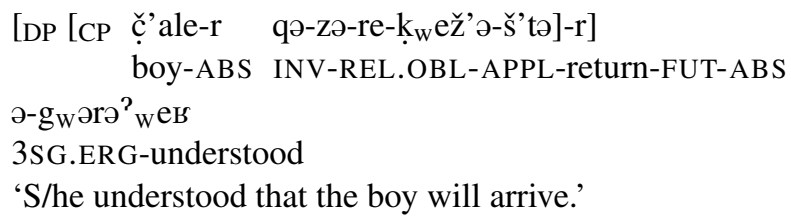

'S/he understood that the boy will arrive.'

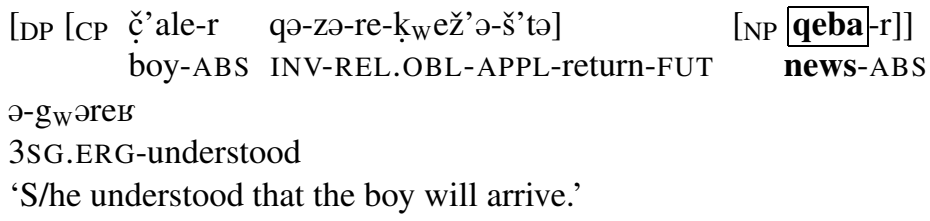

'S/he understood that the boy will arrive.'

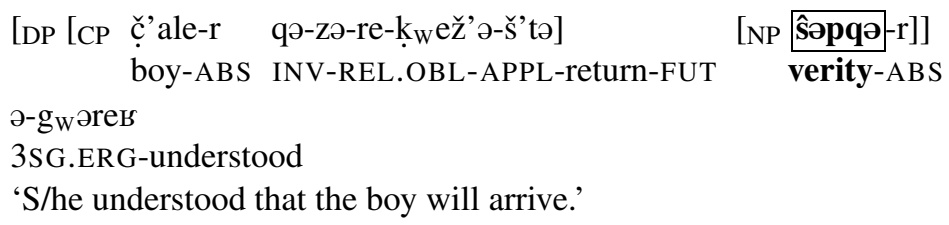

Based on the morphosyntactic similarities in the data in (108)-(110) and on our speakers' intuitions about their truth conditions, we make the following two proposals for Adyghe: first, the nominals like those in boldface and boxed in (109) and (110) are responsible for turning a set of polarity operators into a proposition; second, when not overt, as in (108), a silent version of these nominals occurs, with the same semantic

${ }^{27}$ Thanks to Christopher Kennedy for suggesting this option. 
contribution. Therefore, a more correct rendering of the syntactic structure for the sentence in (108) would be as in (111), with a null nominal head following the relative clause.

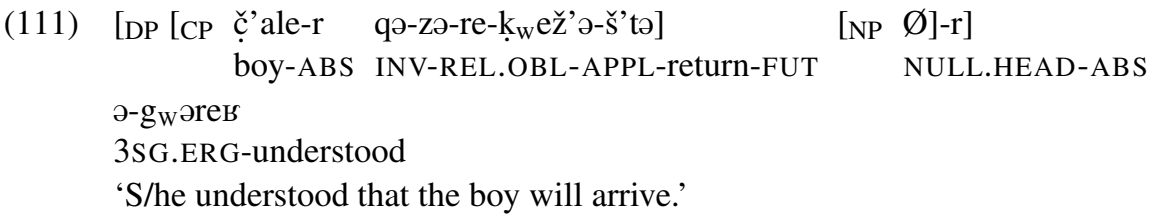

More generally, the structure that we are proposing for a relative clause within a complex DP occurring as the complement of a propositional attitude predicate is the one in (112).

(112) [DP [NP [CP Op 1 [TP $\left.\left.\left.\left.\mathrm{e}_{1}\right]\right][\mathrm{N} \emptyset]\right] \mathrm{D}\right]$

(114) presents a detailed semantic derivation of the bracketed complex DP in (98) (repeated as (113) below) according to our proposal, and shows how the same interpretation as an embedded declarative is achieved.

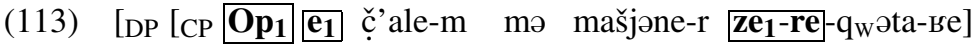

$$
\begin{array}{cl}
\text { [NP Ø]-r]] } & \text { sə-g } \text { w }_{\text {fpšəsas }} \\
\text { NULL.HEAD-ABS } & 1 \text { SG-thought }
\end{array}
$$

'I thought that the boy broke this car.'

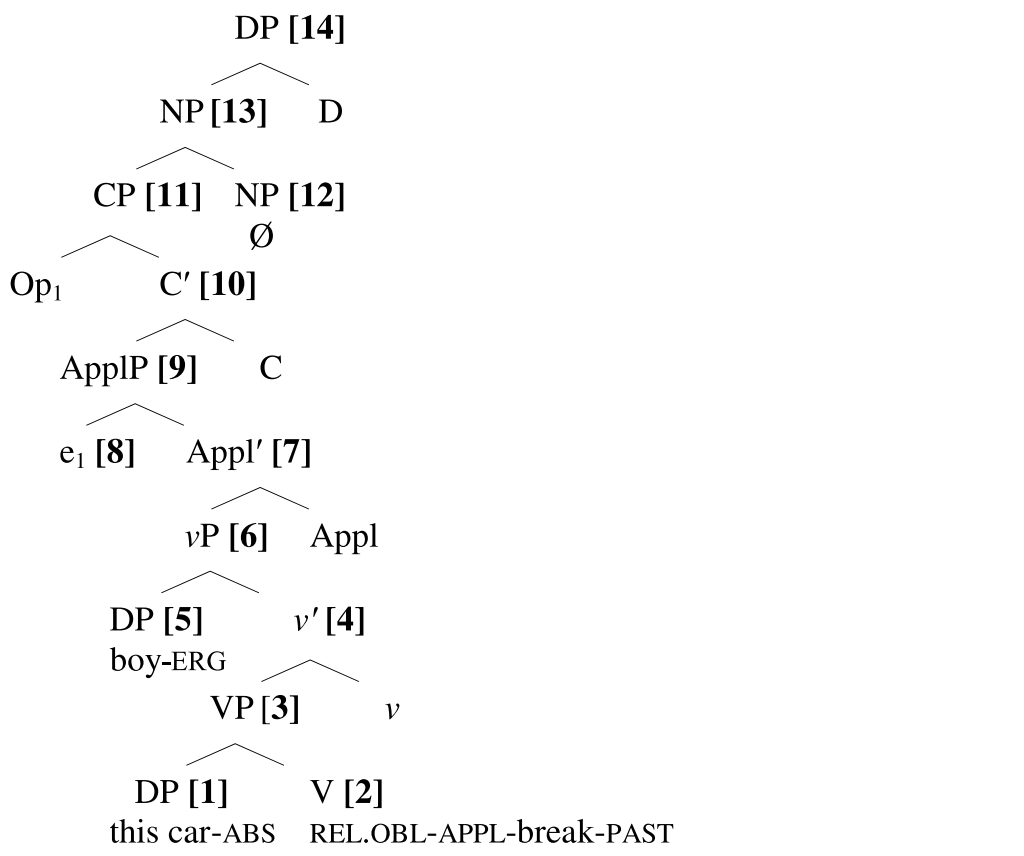


[1]. [DP this car-ABS] $>\mathrm{c}_{<\mathrm{e}>}($ constant $)$

[2]. [v REL.OBL-APPL-break-PAST] $\sim \lambda$ y. $\lambda \mathrm{x} . \lambda \mathrm{w} \cdot \operatorname{break}(\mathrm{w})(\mathrm{y})(\mathrm{x})$

[3]. $\quad \mathrm{VP} \sim>\lambda \mathrm{x} . \lambda \mathrm{w} \cdot \operatorname{break}(\mathrm{w})(\mathrm{c})(\mathrm{x})$

[4]. $\quad v^{\prime} \sim>\lambda \mathrm{x} . \lambda \mathrm{w} . \operatorname{break}(\mathrm{w})(\mathrm{c})(\mathrm{x})($ same as [3])

[5]. [DP boy-ERG] $\sim \mathrm{b}_{<\mathrm{e}>}$ ( constant)

[6]. $\quad v \mathrm{P} \sim>\lambda \mathrm{w} \cdot \operatorname{break}(\mathrm{w})(\mathrm{c})(\mathrm{b})={ }_{\mathrm{def}} \mathrm{p}_{0}$

[7]. $\quad \mathrm{Appl}^{\prime} \sim>\mathrm{p}_{0}$ (same as [6])

[8]. $\mathrm{e}_{1} \sim>\mathrm{f}_{\mathrm{X}<\mathrm{st}, \mathrm{st}>}$ (variable ranging over: $\left.\left\{\mathrm{f}_{\mathrm{POS}} \lambda \mathrm{p} . \mathrm{p}, \mathrm{f}_{\mathrm{NEG}}: \lambda \mathrm{p} . \sim \mathrm{p}\right\}\right)$

[9]. ApplP $\sim \mathrm{f}_{\mathrm{X}}\left(\mathrm{p}_{0}\right)$

[10]. $\mathrm{C}^{\prime} \sim>\mathrm{f}_{\mathrm{X}}\left(\mathrm{p}_{0}\right)$ (same as [9])

[11]. [CP $\left.\mathrm{Op}_{1} \mathrm{C}^{\prime}\right] \sim>\mathrm{f}_{\mathrm{X}} \cdot \mathrm{f}_{\mathrm{X}}\left(\mathrm{p}_{0}\right)$

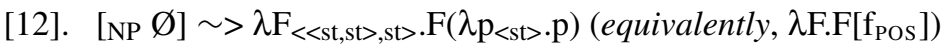

[13]. [NP CP Ø] > $\lambda$ F.F $(\lambda$ p.p $)\left(\lambda f_{X} . f_{X}\left(p_{0}\right)\right)=p_{0}$

[14]. [DP NP D] $\sim>\mathrm{p}_{0}$ (same as [13])

As in the previous semantic derivations, we assume in (114) that the $v \mathrm{P}$ ends up denoting a proposition $\mathrm{p}_{0}[6]$ and the relative clause operator $\left(\mathrm{Op}_{1}\right)$ is in SpecC. This time the operator binds an empty category in the specifier of the applicative projection (ApplP), which introduces the variable ranging over polarity operators [8]. The operator triggers lambda abstraction over the co-indexed gap/variable and returns a function from polarity operators to propositions as the meaning of the CP [11]. The (silent) nominal [12] is defined as a complex function taking a function $\mathrm{F}$ from polarity operators to propositions as its argument and returning just the proposition that constitutes the value of the positive polarity operator. The combination of the silent nominal with the $\mathrm{CP}$ returns the proposition $\mathrm{p}_{0}$ that we started with as the denotation of the $v \mathrm{P}$ [13]. A proposition is the correct semantic object to serve as the argument of a propositional attitude predicate like 'think'. Therefore, type-shifting does not have to apply, the head D is semantically inert, and the whole complex DP inherits the same denotation as the NP, or the proposition $\mathrm{p}_{0}[14]$.

The same overt nominals that can introduce the relative clause interpreted as an embedded declarative in (109) and (110) can also introduce relative clauses that are interpreted as embedded polar interrogatives. (115) shows a familiar relative clause without an overt head, while (116) shows the corresponding construction with one of the special nominals that may serve as the overt head. They are both interpreted as embedded polar interrogatives and our consultants judge them to be truthconditionally equivalent.

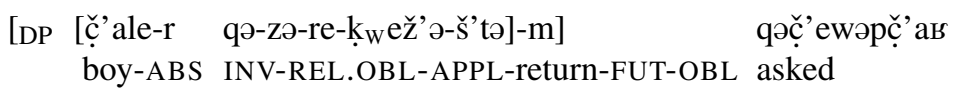

'S/he asked if the boy will arrive.' 


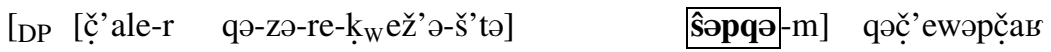

$$
\begin{aligned}
& \text { boy-ABS INV-REL.OBL-APPL-return-FUT verity-OBL asked }
\end{aligned}
$$

'S/he asked if the boy will arrive.'

We also found a nominal that can occur as the head of these relatives but only returns the interrogative interpretation. We gloss it as 'question'. (117) shows that when this nominal occurs as the head of a relative in the complement position of a predicate like 'know', which is compatible with both an interrogative-like or a declarativelike interpretation of its complement (as shown in (101) in above), then only the interrogative-like interpretation is available. On the other hand, with a nominal like 'verity' both interpretations are available (118).

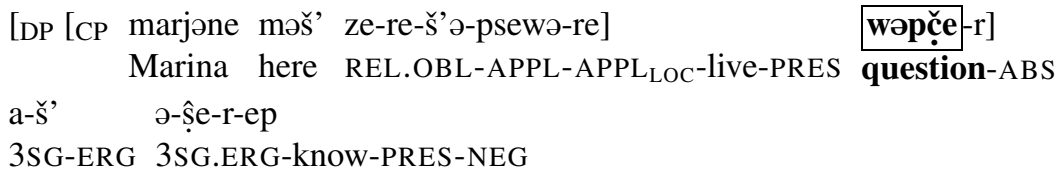

'S/he does not know *that/whether Marina lives here.'

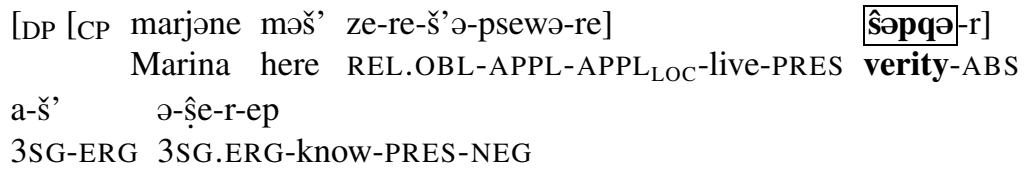

'S/he does not know that/whether Marina lives here.'

We suggest that the syntax of relative clauses that are interpreted as embedded polar interrogatives is identical to the syntax of relative clauses that are interpreted as embedded declaratives. We also suggest that their semantics is similar-the only difference is in the meaning of the (silent) nominals. For example, the relative clause in (119) is interpreted as an embedded polar interrogative; its syntactic structure is given in (120). This structure is identical to the structure in (114) for the relative clause in (113), which is interpreted as an embedded declarative. The semantic derivation is the same as well, at least up to the point where the silent nominal [12] combines with the CP [11]. Therefore, in our discussion of the semantic derivation in (120) below, we will focus only on steps [11] to [14].

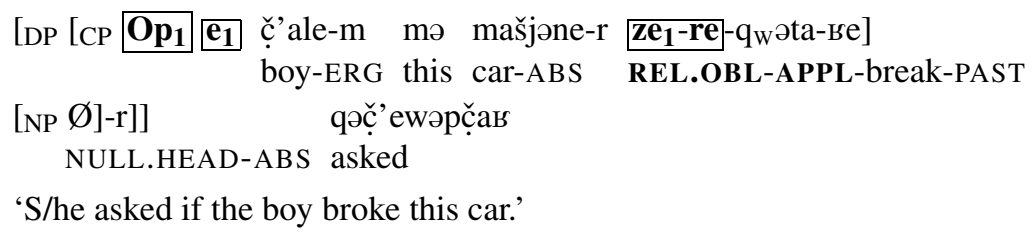


(120)

DP [14]

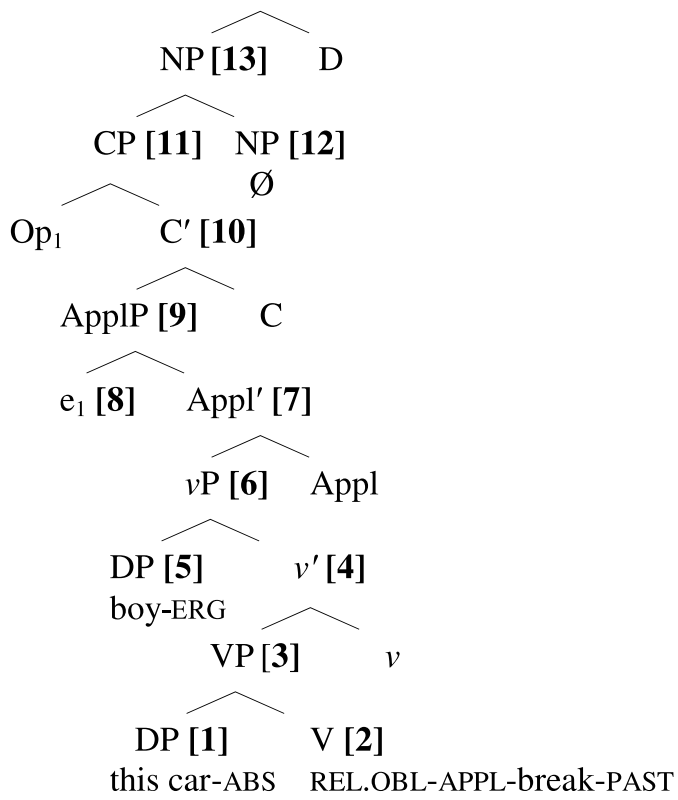

[1]-[10]: Same as the interpretation of the relative in (114): [1]-[10]

[11]. $\quad\left[\mathrm{CP}_{0} O \mathrm{p}_{1} \mathrm{C}^{\prime}\right] \sim>\lambda \mathrm{f}_{\mathrm{X}} \cdot \mathrm{f}_{\mathrm{X}}\left(\mathrm{p}_{0}\right)$ (same as (114): [11])

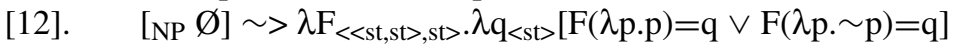
(equivalently, $\left.\lambda \mathrm{F} . \lambda \mathrm{q}\left[\mathrm{F}\left(\mathrm{f}_{\mathrm{POS}}\right)=\mathrm{q} \vee \mathrm{F}\left(\mathrm{f}_{\mathrm{NEG}}\right)=\mathrm{q}\right]\right)$

[13]. $\quad[\mathrm{NP} C \mathrm{CP} \emptyset] \sim>\lambda \mathrm{F} \cdot \lambda \mathrm{q}[\mathrm{F}(\lambda \mathrm{p} . \mathrm{p})=\mathrm{q} \vee \mathrm{F}(\lambda \mathrm{p} . \sim \mathrm{p})=\mathrm{q}]\left(\lambda \mathrm{f}_{\mathrm{X}} . \mathrm{f}_{\mathrm{X}}\left(\mathrm{p}_{0}\right)\right)$ $=\lambda \mathrm{q} \cdot\left[\mathrm{p}_{0}=\mathrm{q} \vee \sim \mathrm{p}_{0}=\mathrm{q}\right]$

[14]. $\quad[D P N P D] \sim>\lambda q\left[\mathrm{p}_{0}=\mathrm{q} \vee \sim \mathrm{p}_{0}=\mathrm{q}\right]$ (same as [13])

The CP in [11] in (120) denotes the same function as in [11] in (114). The silent nominal in [12] now denotes a complex function taking a function $\mathrm{F}$ from polarity operators to propositions as its argument and returning the set containing the two propositions that constitute the values of the positive and negative polarity operators, respectively. The combination of the silent nominal with the $\mathrm{CP}$ returns the set $\left\{p_{0}, \sim p_{0}\right\}$ containing the values of both the positive and the negative operators when applied to $\mathrm{p}_{0}$ [13]. A set of propositions is the correct semantic object for the complement of an interrogative predicate like 'ask'; therefore, no type-shifting is needed, $\mathrm{D}$ is semantically inert, and the whole complex DP inherits the same denotation as the NP, or the set $\left\{\mathrm{p}_{0}, \sim \mathrm{p}_{0}\right\}$ [14]. In conclusion, the semantic import of the silent nominals is the only difference between the semantic derivations in (114) and (120), and, more generally, between the Adyghe constructions that are interpreted as embedded declaratives and those that are interpreted as embedded polar interrogatives. We are assuming that those silent nominals are ambiguous just as the truth-conditionally equivalent overt nominals 'verity', 'news', etc., that we saw in (109), (110), (116), and (118) above are ambiguous.

Before concluding, we offer one more comment on the high applicative prefix rethat characterizes the relative constructions above. All the applicative prefixes we 
saw before could occur not just in relative constructions, but also in plain declarative sentences and license an overt argument. The high applicative re-, instead, is found only in relative constructions and does not occur in root clauses. Although we do not have a principled explanation for this restriction, we would like at least to offer some suggestions. According to our analysis, the high applicative re- is needed to form a relative clause denoting a set of polarity operators, which then combines with those silent or overt special nominals we just discussed. This relative clause formation is due to the lack of non-relative complementizers in Adyghe and, therefore, the impossibility of embedding any tensed clauses but relative clauses (cf. Sect. 8 for further discussion of this issue). But a root clause is not embedded by definition. Therefore, the high applicative re- is not needed and does not occur. In other words, this proposal amounts to the idea that additional functional structure is optional and is projected only when needed (cf. Doherty 1993; Grimshaw 1997; Pesetsky 2000). Specifically, the applicative phrase licensing a polarity operator is not projected if there is no need for an operator in the clause, e.g., in root clauses.

In summary, we have argued that Adyghe uses relative clauses to convey what embedded declaratives and embedded polar interrogatives covey in languages like English. In particular, we have suggested that the way the denotation of a relative clause is turned into the appropriate denotation for the complement of a propositional attitude predicate or an interrogative predicate is by means of a nominal that acts as the head of this relative, is silent most of the time, and has a complex semantics. A small number of nouns can overtly realize the nominal head. These are nominals meaning 'rumor', 'fact' 'truth', 'news', and 'question'. When these nouns occur with a relative containing $z e-r e$ - (the relativizer and the high applicative), though, they all seem to have the same light and "bleached" meaning. In fact, the whole sentence ends up being truth-conditionally equivalent to one with a silent nominal and can be interpreted as either an embedded declarative or an embedded polar interrogative, depending on the matrix predicate (remember that the nominal 'question' behaves differently: it only allows for an interrogative interpretation).

\subsection{How different is Adyghe from other languages?}

The Adyghe relative construction we have just discussed may resemble the construction "the fact/claim/rumor that ..." in English and other languages. In fact, the idea that finite sentential complements are all relative clauses has been proposed for more familiar languages. Kayne (2007) argues that embedded declaratives in English and French form a subset of relative clauses. He suggests that embedded declaratives have the silent head noun fact (cf. also Kiparsky and Kiparsky 1970) which allows that relativization (which relativization is ruled out by the restrictions on the determiners that can occur with fact). A sentence such as (121a) would be structurally identical to (121b) (but with a silent the fact) and they would both be derived from (121c):

a. I know that you are here.

b. I know the fact that you are here.

c. You are here in fact//In fact you are here. 
Closer to home, an analysis similar to Kayne's has independently been proposed for Adyghe. Building on Nichols's (2003) idea, Gerasimov and Lander (2008) suggest that Adyghe clauses with the high applicative $r$ - are relative fact-clauses.

In what follows, we highlight similarities and differences between the Adyghe constructions and the fact/rumor-constructions in more familiar languages and point out some related open issues. Both Adyghe and English can use a small class of meaning-related nominals to introduce clauses that, without those nominals, would be interpreted as embedded interrogatives or declaratives. However, the presence of those nominals affects the interpretation differently in the two languages. In Adyghe, there does not seem to be any relevant meaning difference between the construction with the overt nominal and the construction with the silent nominal. On the other hand, the overt nominal can trigger semantic differences in English, as shown in (122). The sentence in (122a) strongly implies that it is true that the president was elected illegally, unlike the sentences in (122b) and (122c).

a. I know $\underline{\emptyset}$ that the president was elected illegally.

b. I know the claim that the president was elected illegally.

c. I know the rumor that the president was elected illegally.

As we discussed above, all these nominals in Adyghe can trigger both the interrogative-like and the declarative-like interpretations, with the only exception being the nominal 'question', which triggers only the interrogative-like interpretation. On the other hand, most of the English nominals that trigger the declarative-like interpretation do not seem to trigger an interrogative-like interpretation. For instance, nominals like fact, news, claim, or rumor can only introduce a declarative clause, but not an interrogative, as made clear by the different complementizers in (123).

(123) We won't discuss the fact/news/claim/rumor $\{$ that $\} / *\{($ of $)$ whether $\}$ the president was elected illegally.

At the same time, English has nominals like puzzle or problem that can introduce both kinds of clauses and trigger both interpretations, as shown by the acceptability of both complementizers in (124). The overt and silent nominals in Adyghe seem closer to the English puzzle than to the English fact, etc.

(124) We won't discuss the puzzle/problem $\{$ that $\} /\{$ (of) whether $\}$ the president was elected illegally.

The clausal complements of this class of nominals in English are clearly distinguishable between embedded interrogatives and embedded declaratives because they accept different complementizers. In Adyghe, however, there is no difference between the clauses that occur with the nominals: they are all relative clauses. Thus, Adyghe uses relative clauses to convey what is conveyed by embedded declaratives or polar interrogatives in English.

To account for the complex pattern and the various restrictions concerning the Adyghe relative construction we just discussed, a better understanding of the semantics of these constructions across languages would be extremely helpful (maybe even necessary). Unfortunately, we are not aware of any detailed investigations of the semantics of "the fact/claim/rumor that ..." construction (but see Zucchi 1993 and 
Kim 2009 for relevant remarks). It could very well be that further research into these constructions across languages may affect the details of our semantic analysis; for instance, new findings may bear on our assumptions about the meaning of these nominals. Nevertheless, we believe that our core generalization about the relative nature of these clauses will not be affected.

\subsection{Could ze-re be a complementizer?}

Could the analogy with the English construction in Sect. 6.4 suggest that what we have called relative clauses in Sects. 6.2 and 6.3 are actually something else? In particular, why can't the marker(s) ze-re- be analyzed as an interrogative/declarative complementizer, so that the syntax/semantics mapping in Adyghe would look much more similar to the majority of the languages we are familiar with ${ }^{28}$ Such an analysis would capture the syntactic distribution and island effects and would also capitalize on the well-attested parallels between relative and non-relative complementizers like English that, Romance que, Russian čto, etc. (Bresnan 1970: 318; Stahlke 1976; van der Auwera 1985, a.o.).

As far as we know, homophony between declarative and interrogative complementizers is not common across languages - the familiar English contrast between the declarative that (and how - see below) and interrogative if/whether instantiates a typical scenario. No languages that we are familiar with that have homophony between relative and non-relative complementizers can extend the same complementizers to polar interrogatives. Further, there is no independent evidence of any complementizer system in embedded clauses in Adyghe. ${ }^{29}$ Adyghe has only one other kind of embedded clause, besides the relative construction we are investigating. It is uncontroversially an infinitival and converbal TP, not a CP (Polinsky and Potsdam 2006; Potsdam and Polinsky 2012; Höhlig 2007).

If $z e$-re-were to be analyzed as a complementizer, its morphological shape would be totally accidental. Our analysis allows us to decompose it into the relativizer $z e$ (the same marker that appears in the other relative clauses) and the high applicative prefix re-, which distinguishes this relative from the others. A further argument for the relative clause analysis of $z e$-re-clauses comes from the observation that these clauses never stack with those relative clauses whose status is not under dispute. In more familiar languages, a fact-clause and a relative clause can stack, as shown for English in (125a, b), for Japanese in (126), and for Korean in (127). In Adyghe, however, such stacking is impossible regardless of the order of the two clauses $(128 \mathrm{a}, \mathrm{b})$.

a. the fact [that gas consumption is diminishing] [that/which CNN ignored]

b. \%the fact [that/which $\mathrm{CNN}$ ignored] [that gas consumption is diminishing]

\footnotetext{
${ }^{28}$ This suggestion is implicit in Smeets's account: he glosses ze-re- as 'that' (Smeets 1984: 255).

${ }^{29}$ See Rogava and Keraševa $(1966: 75,336,434)$ for explicit statements that Adyghe lacks embedding in the "average standard European" sense; see Gerasimov and Lander (2008) for remarks that no overt complementizers have been reported.
} 
(126) [CNN-ga hookokushi-ta] [shitsugyo-ritsu-ga agatteiru]

CNN-NOM report-PAST unemployment-rate-NOM rising

(to-iu) jijitsu

(COMP-say) fact

'the fact that the unemployment rate is rising that $\mathrm{CNN}$ reported'

(127) $[\mathrm{ku}$ kica-ka enkupha-n] [Libby-ka koso-toy-n] sasil that reporter-NOM mention-ADN Libby-NOM indict-undergo-ADN fact 'the fact that the reporter mentioned that Libby got indicted'

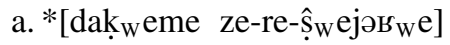

marrying REL.OBL-APPL-desire_have

[m $\mathrm{m}_{\mathrm{w}}$ rat $\varnothing$-qə-s-f-jə- ${ }^{2}{ }_{\mathrm{w}}$ eta-se]

Murat REL.ABS-DIR-1SG.OBL-APPL $\mathrm{BEN}_{\mathrm{BE}}-3$ SG.ERG-deliver-PAST

qeba-r

news-ABS

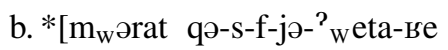

Murat $\varnothing$-REL.ABS-DIR-1SG.OBL-APPL $\mathrm{BEN}_{\mathrm{BEN}}$-3SG.ERG-deliver-PAST

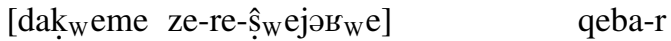

marrying REL.OBL-APPL-desire_have news-ABS

'the news/rumor that she wants to get married which Murat told me'

Note that two uncontroversial relatives (modifying a noun head) cannot stack either (129)-(130), which suggests that whatever the reason for the ban on stacking in Adyghe is, it applies across the board. ${ }^{30}$

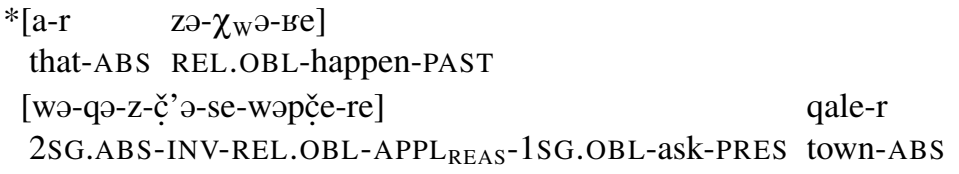

'the town where this happened which you are asking me about/on the account of'

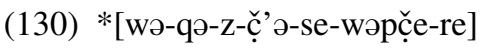

$$
\begin{aligned}
& \text { 2SG.ABS-INV-REL.OBL-APPL REAS-1SG.OBL-ask-PRES } \\
& \text { [a-r zə- } \chi_{w} \partial-\text { - } \\
& \text { that-ABS REL.OBL-happen-PAST town-ABS }
\end{aligned}
$$

'the town that you are asking me about where this happened'

The restriction on stacking and the behavior of embedded declaratives and embedded polar interrogatives argue against the treatment of ze-re- as a complementizer. The relative clause analysis, instead, allows for a uniform account of these data.

\footnotetext{
${ }^{30}$ It is worth noting that the stacking of relative clauses, generally available for postnominal relatives (Hudson 1990: 396; Sag 1997), is much more constrained in head-final languages (Suzuki 2005; Larson and Takahashi 2007). Whatever the reasons behind the ban on the stacking of prenominal relative clauses, this ban is categorical in Adyghe.
} 
Finally, the reader may be tempted to draw a parallel between ze-re- and the English how in a sentence like (131a). This sentence has a reading that is truthconditionally equivalent to (131b), in which the wh-word how has been replaced with the declarative complementizer that. This could be taken as an example of a construction that syntactically looks like a $w h$-construction but semantically behaves like a declarative (cf. Legate 2010).

(131) a. She remembers how Jerry would sit on the porch all day long.

b. She remembers that Jerry would sit on the porch all day long.

Despite their superficial similarity, there are several major differences between the English construction and our Adyghe construction. The English how-complements presuppose the truth of their propositional content. (131) presupposes that Jerry sat on the porch all day long. This is why, if the matrix predicate in (131) is replaced with a non-factive predicate like believe, then the that-clause is still acceptable (132b), but the how-clause no longer is (132a).

a. * She believes how Jerry would sit on the porch all day long.

b. She believes that Jerry would sit on the porch all day long.

On the other hand, Adyghe clauses do not exhibit any presuppositional restrictions. Also, what looks like the very same construction in Adyghe is used to trigger both interrogative-like and declarative-like interpretations, while the English howconstruction with this particular interpretation cannot occur as the complement of an interrogative predicate. In (133a), how is interpreted as a true wh-word, and the whole sentence cannot be interpreted as truth-conditionally equivalent to (133b), in which how has been replaced by the interrogative complementizer whether. But it is precisely the meaning of a sentence like (133b) (and not (133a)) that would be rendered in Adyghe by using ze-re-.

a. She asked how Jerry would sit on the porch all day long.

b. She asked whether Jerry would sit on the porch all day long.

In conclusion, the "high applicative" re- in Adyghe cannot be analogized to the English declarative how.

6.6 Conclusions about "embedded declaratives" and "embedded polar interrogatives"

We have shown that Adyghe does not have syntactic structures that resemble the more familiar embedded declaratives or embedded polar interrogatives in other languages. Once again, the language fills that void by using a relative construction. The corresponding relatives always carry the relativizer $z \mathrm{~V}$ - (like many other relative clauses), but are morphologically distinguishable from the rest of the relatives by the presence of the high applicative re-. We argued that these two prefixes together signal abstraction over a variable associated with a polarity operator. As a result, the relative clause denotes a set of polarity operators. Nevertheless, this cannot be the end of the semantic story since these relative clauses end up being interpreted as either embedded 
declaratives or embedded polar interrogatives. We notice that their semantic behavior is identical to another construction in which the very same kind of relative clause occurs, but this time with an overt head, drawn from a restricted class of abstract nominals such 'news', 'truth', 'question', etc. We conclude that all these relatives (with or without an overt head) have the same syntactic and semantic structure: they are all headed relatives with their (possibly silent) head denoting a function that is responsible for turning the denotation of the clause from a set of polarity operators into a proposition (or a set of propositions).

\section{Adjunct clauses}

So far we have not seen any evidence that Adyghe allows for embedded tensed clauses unless they are relative clauses within a complex DP. This restriction is not accidental. We believe Adyghe has no other way of embedding tensed clauses, and we will speculate more on why this is the case at the end of the paper (Sect. 8). In this section, we will further strengthen our proposal by demonstrating that Adyghe also uses complex DPs embedding a relative clause to convey what tensed adjunct clauses convey in other languages.

Adjuncts in Adyghe can be expressed in three ways. Non-clausal adjuncts are realized by adverbials from a small inventory of true adverbs, or from a larger set of nouns turned into adverbs by means of the adverbial suffix -ew or a postposition (Rogava and Keraševa 1966: 91-95, 383-385). As for expressing clausal adjuncts, one option is to use matrix sentences loosely coordinated with other clauses paratactically, or with the help of particles (Sumbatova 2005; Höhlig 2007; Smeets 1984: Chap. 5). The other option for expressing clausal adjuncts is to make use of complex DPs that contain a relative clause, are marked with oblique case, are not licensed by an applicative head, and can be governed by a postposition. In this section, we focus on the latter option, since it constitutes another example of how Adyghe uses the same 'relative clause' strategy to convey what in other languages would be expressed by means of several dissimilar syntactic structures.

The bracketed string in (134) shows how a tensed temporal adjunct clause is realized in Adyghe. It has all the properties of the headless relative we discussed in Sect. 4: the case marker $(-m)$ at its right edge and the relativizer verbal prefix $z \partial^{-}$ immediately followed by the temporal applicative verbal prefix $\check{s}^{\prime} \partial^{-}$, which together signal that we are dealing with a relative clause with a relativized temporal argument. (135) shows that a very similar headed relative with the temporal nominal 'day/time' as its head can be used to convey a similar meaning.

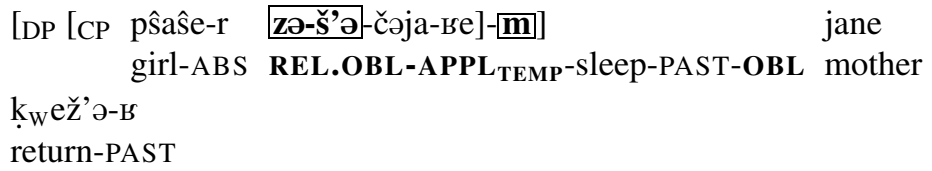

'The mother came back when the girl was asleep.' 


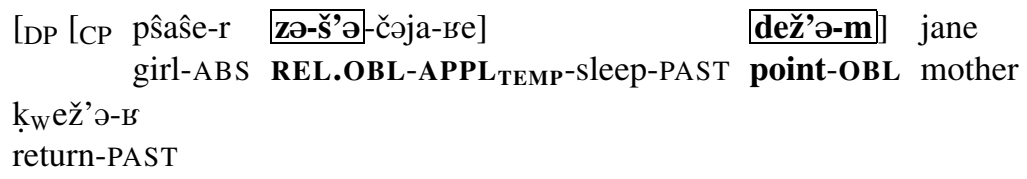

'The mother came back at the time the girl was asleep.'

In (134) and (135), the matrix predicate 'return' does not carry any temporal applicative prefix, which means that the bracketed complex temporal DP with the relative inside is a true adjunct of the matrix clause and not an indirect argument. These "adjunct clauses" are syntactic islands, which of course would be compatible both with the relative clause analysis - the one we pursue - and the regular adjunct clause analysis. However, the morphological signature of these clauses $(z \mathrm{~V}$-marking and applicative heads) is specific to the relative clause analysis.

How is the connection between the adjunct and its matrix clause established in the absence of a postposition? This phenomenon is not peculiar to Adyghe. English and other languages have temporal DPs that seem to behave syntactically and semantically as PPs, though there is no overt P. For instance, the DP that day in the sentence It happened that day behaves syntactically and semantically the same as the PP on that day in It happened on that day. It has been argued that a silent preposition occurs with DPs that behave like PPs (McCawley 1988; also Larson 1985) or with headless/free relatives introduced by when, where, and how in English when they behave like PPs (Caponigro and Pearl 2009). A similar approach can easily be developed for the syntax/semantic mapping of adjunct clauses in Adyghe, but it is not directly relevant for our purposes. What is crucial for us is that Adyghe uses complex DPs containing relative clauses to convey what other languages convey by means of adjunct clauses.

The use of such "adjunct clauses" is extremely productive and involves embedded declaratives, as we discussed in Sect. 6 above. Thus, (136) and (137) show a morphological/syntactic/semantic pattern similar to the one we just saw-except that the relativized argument is introduced by the high applicative re- (discussed in Sect. 6) and the whole bracketed complex DP with a relative inside behaves like an adjunct denoting the cause of the event in the main clause. Note that in this particular example, there is a postposition (paje 'for'/'because') but the structure of the adjunct is not different from the temporal adjunct discussed above. Also, the head in (137) is more generic_an indefinite expression with the meaning 'one'/'something':

$$
\begin{aligned}
& \text { a-r jənstjət }{ }_{\mathrm{W}} \partial \mathrm{t} \partial-\mathrm{m} \text { ç̣eha-B } \\
& \text { 3SG-ABS institute-OBL enter-PAST }
\end{aligned}
$$

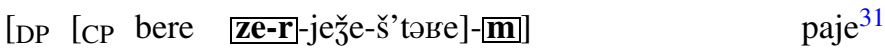

$$
\begin{aligned}
& \text { much REL.OBL-APPL-study-IMPF.PAST-OBL for }
\end{aligned}
$$

'He got into college because he studied a lot.'

(Lit.: 'He got into college on the account of the fact that he studied a lot.')

\footnotetext{
${ }^{31}$ From Sumbatova (2005: ex. 22).
} 


$$
\begin{aligned}
& \text { a-r jonstjət }{ }_{\mathrm{W}} \text { วtว-m ç̌eha-s } \\
& \text { 3SG-ABS institute-OBL enter-PAST } \\
& \text { [DP [CP bere } \mathbf{Z e - r} \text {-ježe-š'təse }] \quad \text { ZO- } \mathbf{m}] \text { paje } \\
& \text { much REL.OBL-APPL-study-IMPF.PAST one-OBL for }
\end{aligned}
$$

'He got into college because he studied a lot.'

(Lit.: 'He got into college on the account of the fact that he studied a lot.')

\section{Conclusions}

Our investigation of clausal embedding in Adyghe has brought us to conclude that this language uses complex DPs containing a headed or headless relative clause to convey what other languages convey by means of not only relative clauses, but also other constructions like embedded constituent interrogatives, embedded declaratives, embedded polar interrogatives, or adjunct clauses. In other words, Adyghe starts from a syntactic construction that is found in other languages (relative clauses) and maps it onto the same meanings that are conveyed by distinct constructions in other languages.. This shows that the familiar syntax/semantics mapping (roughly, a different embedded construction for each meaning) is not the only one available.

Although different, the syntax/semantics interface in Adyghe includes only such mechanisms as concealed questions, polarity operators, and nominals like fact or question, all of which are independently attested not just in Adyghe but also in more familiar languages, as we showed in the previous sections.

This is the core conclusion we arrive at: Adyghe stretches its use of relative clauses further than more familiar languages, but it does nothing in violation of the fundamental principles of language design. Thus, the seeming exoticism of Adyghe is only skin-deep. Under closer scrutiny, it can be accounted for within the existing theories of language structure and meaning.

If our analysis is on the right track, Adyghe is the type of language whose verbs take DPs or TPs, but not CPs as their complements. At the same time, we have found no evidence of any kind of non-relative complementizer in Adyghe. We believe that these two facts-the lack of CP complements and the lack of non-relative complementizers - are related. The lexicon of a language is expected to shape its syntax, and just as there are languages without determiners, there can be languages without certain complementizers. Because of this apparent lexical gap, the large majority of predicates that in other languages would take a CP, in Adyghe only subcategorize for a DP or a PP.

The TP-taking verbs are a smaller class of volitional and aspectual predicates (Kumakhov and Vamling 1998; Polinsky and Potsdam 2006; Potsdam and Polinsky 2012). According to Rizzi (1990: 68), complementizers differ in the feature [ \pm predicative]. Those complementizers that are [+ predicative] can head a clause which can be predicated of an entity. Relative complementizers are predicative, whereas complement clauses are headed by non-predicative complementizers. Tensed complementizers in the relative clause domain, whether overt or silent, thus form a class by themselves. Rizzi's typology correctly predicts that a language may have one type of complementizer but not the other. It remains to be seen if there are languages that 
have only non-predicative complementizers, but no relative clause complementizers. We are not aware of such languages, which may point to an intriguing asymmetry between complementizer types.

Based on our analysis, we can also outline several broader implications which we leave as questions for future research. First, if a language exhibits the embedding of complementizers encoding illocutionary force (as is the case, for example, in Japanese or Korean, where interrogative markers embed freely), then those embedded constructions cannot be relative clauses, since relative clauses lack higher functional projections associated with illocutionary force (Rizzi 1997). Therefore, it is no longer surprising that the interrogative marker - $a$ in Adyghe never embeds, as we saw earlier. This is expected since a relative clause does not have enough functional architecture to host the relevant projection.

Second, recall that our account of Adyghe "embeddings" crucially relies on the independently attested concealed question strategy. If a language does not independently employ concealed questions (as has been proposed for Macedonian-see Caponigro and Heller 2007), it naturally follows that it would not use extensive relativization to convey constituent interrogatives.

Last, if independent evidence is found in a language that its propositional attitude or interrogative predicates do not allow for DP complements, then the same language is expected not to be able to use the Adyghe strategy; that is, it should not use relative clauses embedded within DPs to convey what other languages express with embedded declaratives or interrogatives. Further cross-linguistic work is needed to determine whether these predictions are on the right track.

Open Access This article is distributed under the terms of the Creative Commons Attribution Noncommercial License which permits any noncommercial use, distribution, and reproduction in any medium, provided the original author(s) and source are credited.

\section{References}

Aldridge, Edith. 2004. Ergativity and word order in Austronesian languages. Ph.D. dissertation, Cornell University.

Aldridge, Edith. 2008. Generative approaches to syntactic ergativity. Language and Linguistics Compass: Syntax and Morphology 2: 966-995.

Arkadiev, Peter, and Dmitry Gerassimov. 2007. The peculiar resultative in Adyghe and what it can tell about aspectual composition in the language. Paper presented at the MPI Conference on the Languages of the Caucasus, Leipzig, December 2007. http://www.eva.mpg.de/lingua/conference/07CaucasusConference/pdf/final\%20abstracts\%20english/ArkadievGerasimovAbstract.pdf.

Arkadiev, Peter, and Alexander Letuchiy. 2008. Derivacii antipassivnoj zony v adygejskom jazyke. [Adyghe antipassive derivations]. In Issledovanija po teorii grammatiki, 4: Issledovanija po otglagol'noj derivacii, ed. Sergei Tatevosov, 77-102. Moscow: Jazyki russkoj kul'tury.

Baker, Mark. 1988. Incorporation. Chicago: University of Chicago Press.

Baker, Mark. 2003. Lexical categories. Cambridge: Cambridge University Press.

Bresnan, Joan. 1970. On complementizers: toward a syntactic theory of complement types. Foundations of Language 6: 297-321.

Broschart, Jürgen. 1997. Why Tongan does it differently: categorial distinctions in a language without nouns and verbs. Linguistic Typology 1: 123-165.

Caponigro, Ivano. 2002. Free relatives as DPs with a silent D and a CP complement. In Proceedings of the western conference on linguistics 2000 (WECOL 2000), ed. Vida Samiian, 140-150. Fresno: California State University. 
Caponigro, Ivano. 2004. The semantic contribution of wh-words and type shifts: evidence from free relatives crosslinguistically. In Proceedings from semantics and linguistic theory (SALT) XIV, ed. Robert B. Young, 38-55. Ithaca: CLC Publications, Cornell University.

Caponigro, Ivano, and Daphna Heller. 2007. The non concealed nature of free relatives: implications for connectivity crosslinguistically. In Direct compositionality, eds. Chris Barker, and Pauline Jacobson, 37-263. Oxford: Oxford University Press.

Caponigro, Ivano, and Lisa Pearl. 2009. The nominal nature of where, when, and how: evidence from free relatives. Linguistic Inquiry 40: 155-164.

Chierchia, Gennaro. 1998. Reference to kinds across languages. Natural Language Semantics 6: 339-405.

Chung, Sandra. 1998. The design of agreement. Chicago: University of Chicago Press.

Colarusso, John. 1992. A grammar of the Kabardian language. Calgary: University of Calgary Press.

Colarusso, John. 2006. Kabardian (East Circassian). Munich: LINCOM Europa.

Dayal, Veneeta. 2004. Number marking and (in)definiteness in kind terms. Linguistics and Philosophy 27: 393-450.

de Vries, Mark. 2002. The syntax of relativization. Utrecht: LOT.

den Dikken, Marcel, Andre Meinunger, and Chris Wilder. 2000. Pseudoclefts and ellipsis. Studia Linguistica 54: 41-89.

Doherty, Cathal. 1993. Clauses without That: the case for bare sentential complementation in English. Ph.D dissertation, University of California, Santa Cruz.

Frana, Ilaria. 2006. The de re analysis of concealed questions. A unified approach to definite and indefinite concealed questions. In Proceedings from semantics and linguistic theory (SALT) XVI, eds. Masayuki Gibson, and Jonathan Howell, 17-34. http://ecommons.library.cornell.edu/bitstream/ 1813/7578/1/salt16_frana_17_34.pdf.

Gerasimov, Dmitry, and Yury Lander. 2008. Reljativizacija pod maskoj nominalizacii i faktivnyj argument $\mathrm{v}$ adygejskom jazyke. In Issledovanija po teorii grammatiki, 4: Issledovanija po otglagol'noj derivacii, ed. Sergei Tatevosov, 290-313. Moscow: Jazyki russkoj kul'tury.

Gordon, Matthew, and Ayla Applebaum. 2006. Phonetic structures of Turkish Kabardian. Journal of the International Phonetic Association 36: 159-186.

Grimshaw, Jane. 1997. Projection, heads, and optimality. Linguistic Inquiry 28: 373-422.

Groos, Anneke, and Henk van Riemsdijk. 1981. Matching effects in free relatives: a parameter of core grammar. In Theory of markedness in generative grammar, eds. Adriana Belletti, Luciana Brandi, and Luigi Rizzi, 171-216. Pisa: Scuola Normale Superiore.

Guerzoni, Elena. 2004. Even NPIs in Yes-No questions. Natural Language Semantics 12: 319-343.

Hamblin, Charles L. 1973. Questions in Montague English. Foundations of Language 10: 41-53.

Heim, Irene. 1979. Concealed questions. In Semantics from different points of view, eds. Rainer Bäuerle, Urs Egli, and Arnim von Stechow, 51-60. Berlin: Springer.

Hewitt, Brian. 1998. The languages of the Caucasus: scope for study and survival. London: SOAS.

Hewitt, George. 2004. Introduction to the study of the languages of the Caucasus. München: LINCOM Euro.

Himmelmann, Nikolaus. 2008. Lexical categories and voice in Tagalog. In Voice and grammatical relations in Austronesian languages, eds. Peter Austin, and Simon Musgrave, 247-293. Stanford: CSLI.

Höhlig, Monika. 2007. Non-finite verbal constructions in Adyghe text: verbal suffix $-s$. Paper presented at the MPI Conference on the Languages of the Caucasus, Leipzig, December 2007. http://www.eva.mpg.de/lingua/conference/07-CaucasusConference/pdf/final\%20abstracts $\% 20$ english/HoehligAbstract.pdf.

Hudson, Richard. 1990. English word grammar. Oxford: Blackwell.

Jacobsen, William. 1979. Noun and verb in Nootkan. In The Victoria conference on northwestern languages, ed. Barbara Efrat, 83-155. Victoria: British Columbia Provincial Museum.

Jacobson, Pauline. 1994. Binding connectivity in copular sentences. In Proceedings from semantics and linguistic theory (SALT) IV, eds. Mandy Harvey, and Lynn Santelmann, 161-178. Ithaca: Cornell University.

Jacobson, Pauline. 1995. On the quantificational force of English free relatives. In Quantification in natural language, eds. Emmon Bach, Eloise Jelinek, Angelika Kratzer, and Barbara H. Partee, 451-486. Dordrecht: Kluwer Academic.

Karttunen, Lauri. 1977. Syntax and semantics of questions. Linguistics and Philosophy 1: 1-44.

Kayne, Richard. 2007. Some thoughts on grammaticalization. The case of That. Paper presented at the XVIIIe Conférence international de linguistique historique, UQAM, Montréal, August 2007.

Keraševa, Zejnab I. 1957. Osobennosti šapsugskogo dialekta adygejskogo jazyka. Maykop: Adygejskoe knižnoe izd. 
Kim, Min-Joo. 2009. E-type anaphora and three types of Kes-construction in Korean. Natural Language and Linguistic Theory 27: 345-377.

Kinkade, M. Dale. 1983. Salish evidence against the universality of 'noun' and 'verb'. Lingua 60: 25-40.

Kiparsky, Paul, and Carol Kiparsky. 1970. Fact. In Progress in linguistics, eds. Manfred Bierwisch and Karl E. Heidolph, 143-173. The Hague: Mouton.

Kumakhov, Mukhadin, and Karina Vamling. 1998. Dopolnitel'nye konstrukcii v kabardinskom jazyke. Lund: Lund University Department of Linguistics.

Kumakhov, Mukhadin, Karina Vamling, and Zara Kumakhova. 1996. Ergative case in the Circassian languages. Lund University Working Papers 45: 93-111.

Lander, Yury. 2004. A relative intrigue in Adyghe. Paper presented at the first international conference on syntax of the world's languages, Leipzig, August 2004.

Lander, Yury. 2005. Pronominal'nye argumenty i adjunktnye imennye gruppy v adygejskom jazyke. [Pronominal arguments and nominal adjuncts in Adyghe.] Ms., Russian State University for the $\mathrm{Hu}-$ manities.

Lander, Yury. 2009a. Unexpected applicatives and morphological compositionality in Adyghe. Paper presented at the Conference on Morphology of the World's Languages. University of Leipzig, June 2009. http://www.uni-leipzig.de/ exponet/mowl/Handouts/Lander.pdf.

Lander, Yury. 2009b. Množestvennaja reljativizacija: podlinnaja i mnimaja. In Aspekty polisintetizma: Očerki po grammatike adygejskogo jazyka, ed. Yakov Testelets, 612-653. Moscow: Russian University for the Humanities.

Lander, Yury, and Yakov Testelets. 2006. Nouniness and specificity: Circassian and Wakashan. Paper presented at the Conference "Universality and particularity in parts-of-speech systems." University of Amsterdam, June 2006.

Larson, Richard K.. 1985. Bare-NP adverbs. Linguistic Inquiry 16: 595-621.

Larson, Richard K., and Naoko Takahashi. 2007. Order and interpretation in prenominal relative clauses. In Proceedings of the workshop on Altaic formal linguistics II. Vol. 54 of MIT working papers in linguistics, 101-120. Cambridge: MITWPL.

Lasnik, Howard, and Tim Stowell. 1991. Weakest crossover. Linguistic Inquiry 22: 687-720.

Legate, Julie Anne. 2008. Morphological and abstract case. Linguistic Inquiry 39: 55-101.

Legate, Julie Anne. 2010. On how how is used instead of that. Natural Language and Linguistic Theory 28: 121-134.

Lehmann, Christian. 1984. Der Relativsatz. Typologie seiner Strukturen, Theorie seiner Funktionen, Kompendium seiner Grammatik. Tubingen: G. Narr.

Letuchiy, Alexander B. 2007. Reciprocals, reflexives, comitatives, and sociatives in Adyghe. In Reciprocal constructions, ed. Vladimir Nedjalkov, 773-811. Amsterdam: Benjamins.

Lewis, M. Paul, ed. 2009. Ethnologue: languages of the world, 6th edn. Dallas: SIL International. Online version: http://www.ethnologue.com/.

McCawley, James. 1988. Adverbial NPs: bare or clad in see-through garb? Language 64: 583-590.

Montague, Richard. 1973. The proper treatment of quantification in English. In Approaches to natural language, eds. Jaakko Hintikka, Julius M.E. Moravcsik, and Patrick Suppes, 221-242. Dordrecht: Reidel.

Nathan, Lance. 2006. On the interpretation of concealed questions. Ph.D. dissertation, MIT.

Nichols, Lynn. 2003. Attitude evaluation in complex NPs. In Formal approaches to functional forces in grammar, eds. Andrew Carnie, and Heidi Harley, 155-164. Amsterdam: Benjamins.

O'Herin, Brian. 2001. Abaza applicatives. Language 77: 477-493.

O'Herin, Brian. 2002. Case and agreement in Abaza. Arlington: University of Texas Press.

Partee, Barbara H. 1986. Noun phrase interpretation and type-shifting principles. In Studies in discourse representation theory and the theory of generalized quantifiers, eds. Jeroen Groenendijk, Dick de Jongh, and Martin Stokhof, 115-143. Dordrecht: Foris.

Pearson, Matthew. 2005. The Malagasy subject/topic as an A' element. Natural Language and Linguistic Theory 23: 381-457.

Pesetsky, David. 2000. Phrasal movement and its kin. Cambridge: MIT Press.

Polinsky, Maria. 2008. Applicative constructions. In The world atlas of language structures online, eds. Martin Haspelmath, Matthew Dryer, David Gil, and Bernard Comrie, Munich: Max Planck Digital Library. http://wals.info/feature/109.

Polinsky, Maria, and Eric Potsdam. 2006. Expanding the scope of control and raising. Syntax 9: 171-192.

Potsdam, Eric. 2007. Malagasy sluicing and its consequences for the identity requirement on ellipsis. Natural Language and Linguistic Theory 25: 577-613. 
Potsdam, Eric. 2009. Austronesian verb-initial languages and wh-question strategies. Natural Language and Linguistic Theory 27: 737-771.

Potsdam, Eric, and Maria Polinsky. 2011, in press. Questions and word order in Polynesian. In: Morphological and syntactic aspects of Oceanic languages, eds. Claire Moyse-Faurie and Joachim Sabel. Berlin: Mouton de Gruyter.

Potsdam, Eric, and Maria Polinsky. 2012, in press. Backward Raising. Syntax.

Pylkkänen, Liina. 2008. Introducing arguments. Cambridge: MIT Press.

Quine, Willard V.O. 1960. Word and object. Cambridge: MIT Press.

Rizzi, Luigi. 1990. Relativized minimality. Cambridge: MIT Press.

Rizzi, Luigi. 1997. The fine structure of the left periphery. In Elements of grammar, ed. Liliane Haegeman, 281-337. Dordrecht: Kluwer Academic.

Rogava, Georgij V., and Zejnab I. Keraševa. 1966. Grammatika adygejskogo jazyka. Maykop: Krasnodarskoe knižn. izd.

Romero, Maribel. 2006. On concealed questions. In Proceedings from semantics and linguistic theory (SALT) XVI, eds. Masayuki Gibson, and Jonathan Howell, 208-227. http://ecommons.library. cornell.edu/bitstream/1813/7589/1/salt16_romero_208_227.pdf.

Romero, Maribel, and Chung-hye Han. 2004. On negative Yes/No questions. Linguistics and Philosophy 27: 609-658.

Sag, Ivan. 1997. English relative clause constructions. Journal of Linguistics 33: 431-483.

Sharvit, Yael. 1999. Connectivity in specificational sentences. Natural Language Semantics 7: 299-304.

Smeets, Rijks. 1984. Studies in West Circassian phonology and morphology. Leiden: Leiden University Press.

Smeets, Rijks. 1992. On valencies, actants and actant coding in Circassian. In Caucasian perspectives, ed. George B. Hewitt, 98-144. München: LINCOM Europa.

Stahlke, Herbert. 1976. Which that. Language 49: 19-46.

Sumbatova, Nina. 2005. Information structure and clause combining in Adyghe. Paper presented at INALCO, Paris, December 2005.

Sumbatova, Nina. 2009. Kommunikativnaja struktura adygejskogo predloženija: perspektiva i focus. In Aspekty polisintetizma: Očerki po grammatike adygejskogo jazyka, ed. Yakov Testelets, 559-611. Moscow: Russian University for the Humanities.

Suzuki, Miki. 2005. Clause stacking and antisymmetry in Japanese relative clauses. Ph.D. Dissertation, CUNY Graduate Center.

Testelets, Yakov, ed. 2009. Aspekty polisintetizma: Očerki po grammatike adygejskogo jazyka. Moscow: Russian University for the Humanities.

van der Auwera, Johan. 1985. Relative that - a centennial dispute. Journal of Linguistics 21: 149-179.

van Eijk, Jan, and Thomas Hess. 1986. Noun and verb in Salish. Lingua 69: 319-331.

van Riemsdijk, Henk. 2005. Free relatives: a syntactic case study. In The Blackwell companion to syntax, eds. Martin Everaert, and Henk van Riemsdijk, Oxford: Blackwell.

Woolford, Ellen. 2006. Lexical case, inherent case, and argument structure. Linguistic Inquiry 37: 111130.

Zimmermann, Ede. 1993. On the proper treatment of opacity in certain verbs. Natural Language Semantics 1: 149-179.

Zucchi, Alessandro. 1993. The language of propositions and events. Dordrecht: Kluwer Academic. 